4

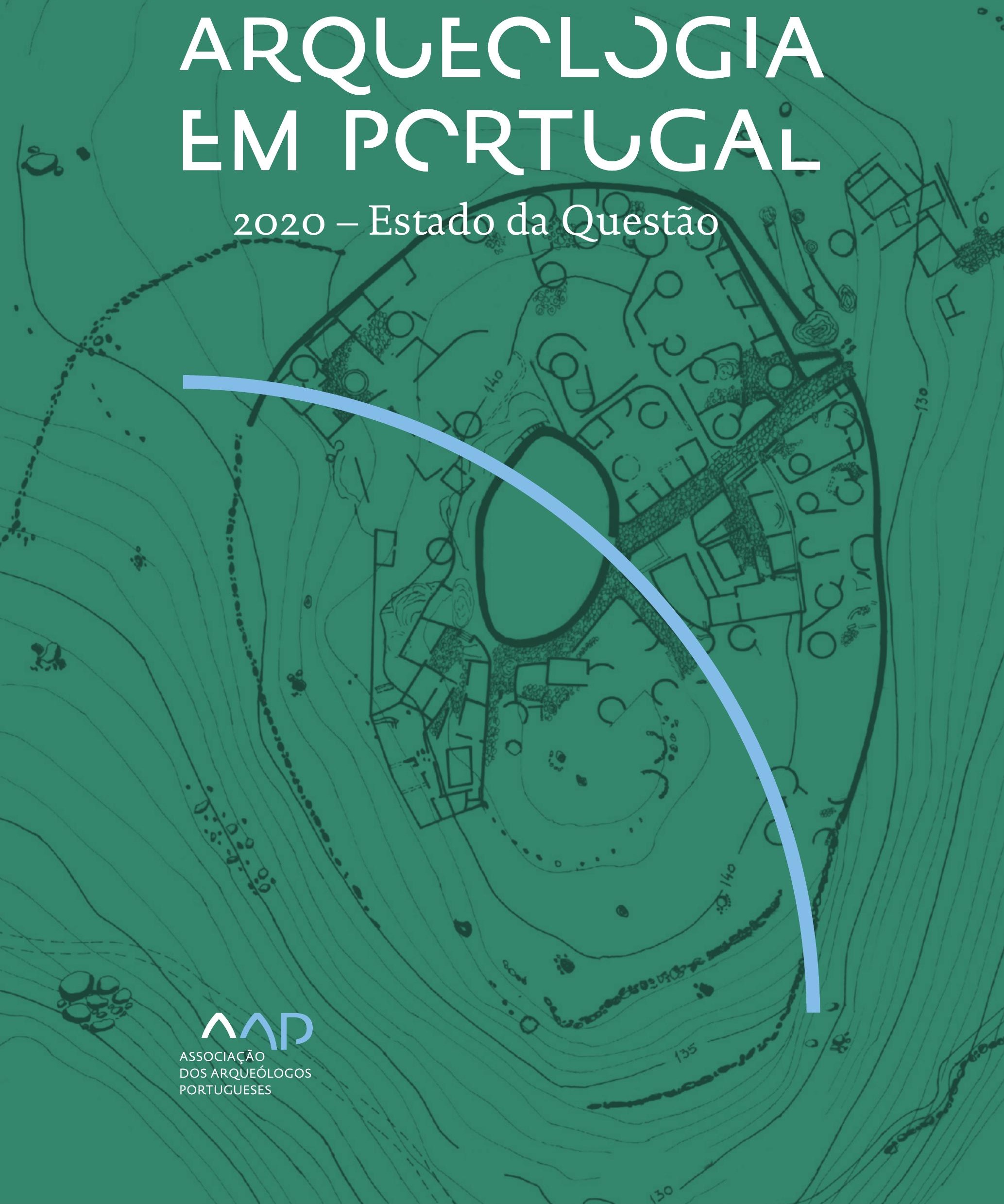


Coordenação editorial: José Morais Arnaud, César Neves e Andrea Martins Design gráfico: Flatland Design

AAP - ISBN: 978-972-9451-89-8

CITCEM - ISBN: 978-989-8970-25-1

Associação dos Arqueólogos Portugueses e CITCEM

Lisboa, 2020

O conteúdo dos artigos é da inteira responsabilidade dos autores. Sendo assim a Associação dos Arqueólogos Portugueses declina qualquer responsabilidade por eventuais equívocos ou questões de ordem ética e legal.

Desenho de capa:

Planta do castro de Monte Mozinho (Museu Municipal de Penafiel).

\section{$\hat{\wedge} \mathrm{P}$}

DOS ARQUEÓLOGOS PORTUGUESES

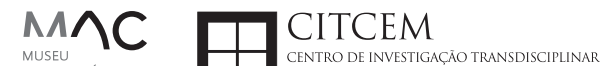
MUSEU
ARQUELLÓGICO
DO CARMO
U.PORTO

FLUP FACULDADE DE LETRAS
UNIVERSIDADE DO PORTO

Apoio

EC para a Ciência 


\section{Índice}

15 Prefácio

José Morais Arnaud

\section{Historiografia e Teoria}

17 Território, comunidade, memória e emoção: a contribuição da história da arqueologia (algumas primeiras e breves reflexões)

Ana Cristina Martins

25 Como descolonizar a arqueologia portuguesa?

Rui Gomes Coelho

41 Arqueologia e Modernidade: uma revisitação pessoal e breve de alguns aspetos da obra homónima de Julian Thomas de 2004

Vítor Oliveira Jorge

57 Dados para a História das Mulheres na Arqueologia portuguesa, dos finais do século XIX aos inícios do século XX: números, nomes e tabelas

Filipa Dimas / Mariana Diniz

73 Retractos da arqueologia portuguesa na imprensa: (in)visibilidades no feminino

Catarina Costeira / Elsa Luís

85 Arqueologia e Arqueólogos no Norte de Portugal Jacinta Bugalhão

101 Vieira Guimarães (1864-1939) e a arqueologia em Tomar: uma abordagem sobre o território e as gentes

João Amendoeira Peixoto / Ana Cristina Martins

115 Os memoráveis? A arqueologia algarvia na imprensa nacional e regional na presente centúria (2001-2019): características, visões do(s) passado(s) e a arqueologia

enquanto marca

Frederico Agosto / João Silva

129 A Evolução da Arqueologia Urbana e a Valorização Patrimonial no Barlavento Algarvio: Os casos de Portimão e Silves

Artur Mateus / Diogo Varandas / Rafael Boavida

\section{Gestão, Valorização e Salvaguarda do Património}

145 O Caderno Reivindicativo e as condições de trabalho em Arqueologia Miguel Rocha / Liliana Matias Carvalho / Regis Barbosa / Mauro Correia / Sara Simões / Jacinta Bugalhão / Sara Brito / Liliana Veríssimo Carvalho / Richard Peace / Pedro Peça / Cézer Santos

155 Os Estudos de Impacte Patrimonial como elemento para uma estratégia sustentável de minimização de impactes no âmbito de reconversões agrícolas Tiago do Pereiro

165 Salvaguarda de Património arqueológico em operações florestais: gestão e sensibilização Filipa Bragança / Gertrudes Zambujo / Sandra Lourenço / Belém Paiva / Carlos Banha / Frederico Tatá Regala / Helena Moura / Jacinta Bugalhão / João Marques / José Correia / Pedro Faria / Samuel Melro

179 Os valores do Património: uma investigação sobre os Sítios Pré-históricos de Arte Rupestre do Vale do Rio Côa e de Siega Verde José Paulo Francisco 
189 Conjugando recursos arqueológicos e naturais para potenciar as visitas ao Geoparque Litoral de Viana do Castelo (Noroeste de Portugal)

Hugo A. Sampaio / Ana M.S. Bettencourt / Susana Marinho / Ricardo Carvalhido

203 Áreas de Potencial Arqueológico na Região do Médio Tejo: Modelo Espacial Preditivo Rita Ferreira Anastácio / Ana Filipa Martins / Luiz Oosterbeek

223 Património Arqueológico e Gestão Territorial: O contributo da Arqueologia para a revisão do PDM de Avis

Ana Cristina Ribeiro

237 A coleção arqueológica do extinto Museu Municipal do Porto - Origens, Percursos e Estudos

Sónia Couto

251 Valpaços - uma nova carta arqueológica

Pedro Pereira / Maria de Fátima Casares Machado

263 Arqueologia na Cidade de Peniche

Adriano Constantino / Luís Rendeiro

273 Arqueologia Urbana: a cidade de Lagos como caso de Estudo Cátia Neto

285 Estratégias de promoção do património cultural subaquático nos Açores. O caso da ilha do Faial

José Luís Neto / José Bettencourt / Luís Borges / Pedro Parreira

297 Carta Arqueológica da Cidade Velha: Uma primeira abordagem

Jaylson Monteiro / Nireide Tavares / Sara da Veiga / Claudino Ramos / Edson Brito /

Carlos Carvalho / Francisco Moreira / Adalberto Tavares

311 Antropologia Virtual: novas metodologias para a análise morfológica e funcional Ricardo Miguel Godinho / Célia Gonçalves

\section{Didáctica da Arqueologia}

327 Como os projetos de Arqueologia podem contribuir para uma comunidade culturalmente mais consciente Alexandra Figueiredo / Claúdio Monteiro / Adolfo Silveira / Ricardo Lopes

337 Educação Patrimonial - Um cidadão esclarecido é um cidadão ativo! Ana Paula Almeida

351 A aproximação da Arqueologia à sala de aula: um caso de estudo no $3^{\circ}$ ciclo do Ensino Básico Luís Serrão Gil

363 Arqueologia 3.o - Pensar e comunicar a Arqueologia para um futuro sustentável Mónica Rolo

377 “Conversa de Arqueólogos" - Divulgar a Arqueologia em tempos de Pandemia Diogo Teixeira Dias

389 Escola Profissional de Arqueologia: desafios e oportunidades Susana Nunes / Dulcineia Pinto / Júlia Silva / Ana Mascarenhas

399 Os Museus de Arqueologia e os Jovens: a oferta educativa para o público adolescente Beatriz Correia Barata / Leonor Medeiros

411 O museu universitário como mediador entre a ciência e a sociedade: o exemplo da secção de arqueologia no Museu de História Natural e da Ciência da Universidade do Porto (MHNC-UP)

Rita Gaspar 
421 Museu de Lanifícios: Real Fábrica de Panos. Atividades no âmbito da Arqueologia Beatriz Correia Barata / Rita Salvado

427 Arqueologia Pública e o caso da localidade da Mata (Torres Novas) Cláudia Manso / Ana Rita Ferreira / Cristiana Ferreira / Vanessa Cardoso Antunes

431 Do sítio arqueológico ao museu: um percurso (também) didático Lídia Fernandes

447 Estão todos convidados para a Festa! E para dançar também... O projecto do Serviço Educativo do Museu Arqueológico do Carmo na $5^{\underline{a}}$ Edição da Festa da Arqueologia Rita Pires dos Santos

459 O “Clã de Carenque”, um projeto didático de arqueologia Eduardo Gonzalez Rocha

469 Mediação cultural: peixe que puxa carroça nas Ruínas Romanas de Troia Inês Vaz Pinto / Ana Patrícia Magalhães / Patrícia Brum / Filipa Santos

481 Didática Arqueológica, experiências do Projeto Mértola Vila Museu Maria de Fátima Palma / Clara Rodrigues / Susana Gómez / Lígia Rafael

\section{Arte Rupestre}

497 Os inventários de arte rupestre em Portugal Mila Simões de Abreu

513 O projeto FIRST-ART - conservação, documentação e gestão das primeiras manifestações de arte rupestre no Sudoeste da Península Ibérica: as grutas do Escoural e Maltravieso Sara Garcês / Hipólito Collado / José Julio García Arranz / Luiz Oosterbeek / António Carlos Silva / Pierluigi Rosina / Hugo Gomes / Anabela Borralheiro Pereira / George Nash / Esmeralda Gomes / Nelson Almeida / Carlos Carpetudo

523 Trabalhos de documentação de arte paleolítica realizados no âmbito do projeto PalæoCôa André Tomás Santos / António Fernando Barbosa / Luís Luís / Marcelo Silvestre / Thierry Aubry

537 Imagens fantasmagóricas, silhuetas elusivas: as figuras humanas na arte do Paleolítico Superior da região do Côa Mário Reis

$55^{1}$ Os motivos zoomórficos representados nas placas de tear de Vila Nova de São Pedro (Azambuja, Portugal) Andrea Martins / César Neves / José M. Arnaud / Mariana Diniz

571 Arte Rupestre do Monte de Góios (Lanhelas, Caminha). Síntese dos resultados dos trabalhos efectuados em 2007-2009 Mário Varela Gomes

599 Gravuras rupestres de barquiformes no Monte de S. Romão, Guimarães, Noroeste de Portugal Daniela Cardoso

613 Círculos segmentados gravados na Bacia do Rio Lima (Noroeste de Portugal): contributos para o seu estudo Diogo Marinho / Ana M.S. Bettencourt / Hugo Aluai Sampaio

631 Equídeos gravados no curso inferior do Rio Mouro, Monção (NW Portugal). Análise preliminar Coutinho, L.M. / Bettencourt, A.M.S / Sampaio, Hugo A.S

645 Paletas na Arte Rupestre do Noroeste de Portugal. Inventário preliminar Bruna Sousa Afonso / Ana M. S. Bettencourt / Hugo A. Sampaio 


\section{Pré-História}

661 O projeto Miño/Minho: balanço de quatro anos de trabalhos arqueológicos Sérgio Monteiro-Rodrigues / João Pedro Cunha-Ribeiro / Eduardo Méndez-Quintas / Carlos Ferreira / Pedro Xavier / José Meireles / Alberto Gomes / Manuel Santonja / Alfredo Pérez-González

677 A ocupação paleolítica da margem esquerda do Baixo Minho: a indústria lítica do sítio de Pedreiras 2 (Monção, Portugal) e a sua integração no contexto regional Carlos Ferreira / João Pedro Cunha-Ribeiro / Sérgio Monteiro-Rodrigues / Eduardo Méndez-Quintas / Pedro Xavier / José Meireles / Alberto Gomes / Manuel Santonja / Alfredo Pérez-González

693 O sítio acheulense do Plistocénico médio da Gruta da Aroeira Joan Daura / Montserrat Sanz / Filipa Rodrigues / Pedro Souto / João Zilhão

703 As sociedades neandertais no Barlavento algarvio: modelos preditivos com recurso aos SIG

Daniela Maio

715 A utilização de quartzo durante o Paleolítico Superior no território dos vales dos rios Vouga e Côa

Cristina Gameiro / Thierry Aubry / Bárbara Costa / Sérgio Gomes / Luís Luís / Carmen Manzano / André Tomás Santos

733 Uma perspetiva diacrónica da ocupação do concheiro do Cabeço da Amoreira (Muge, Portugal) a partir da tecnologia lítica Joana Belmiro / João Cascalheira / Célia Gonçalves

745 Novos dados sobre a Pré-história Antiga no concelho de Palmela. A intervenção arqueológica no sítio do Poceirão I

Michelle Teixeira Santos

757 Problemas em torno de Datas Absolutas Pré-Históricas no Norte do Alentejo Jorge de Oliveira

771 Povoamento pré-histórico nas áreas montanhosas do NO de Portugal: o Abrigo 1 de Vale de Cerdeira Pedro Xavier / José Meireles / Carlos Alves

783 Apreciação do povoamento do Neolítico Inicial na Baixa Bacia do Douro. A Lavra I (Serra da Aboboreira) como caso de estudo Maria de Jesus Sanches

797 O Processo de Neolitização na Plataforma do Mondego: os dados do Sector C do Outeiro dos Castelos de Beijós (Carregal do Sal)

João Carlos de Senna-Martinez / José Manuel Quintã Ventura / Andreia Carvalho / Cíntia Maurício

823 Novos trabalhos na Lapa da Bugalheira (Almonda, Torres Novas) Filipa Rodrigues / Pedro Souto / Artur Ferreira / Alexandre Varanda / Luís Gomes / Helena Gomes / João Zilhão

837 A pedra polida e afeiçoada do sítio do Neolítico médio da Moita do Ourives (Benavente, Portugal)

César Neves

857 Casal do Outeiro (Encarnação, Mafra): novos contributos para o conhecimento do povoamento do Neolítico final na Península de Lisboa.

Cátia Delicado / Carlos Maneira e Costa / Marta Miranda / Ana Catarina Sousa

873 Stresse infantil, morbilidade e mortalidade no sítio arqueológico do Neolítico Final/ Calcolítico ( $4^{\circ}$ e $3^{\circ}$ milénio a.C.) do Monte do Carrascal 2 (Ferreira do Alentejo, Beja) Liliana Matias de Carvalho / Sofia N. Wasterlain 
885 Come together: O Conjunto Megalítico das Motas (Monção, Viana do Castelo) e as expressões Campaniformes do Alto Minho Ana Catarina Basílio / Rui Ramos

899 Trabalhos arqueológicos no sítio Calcolítico da Pedreira do Poio Carla Magalhães / João Muralha / Mário Reis / António Batarda Fernandes

913 O sítio arqueológico de Castanheiro do Vento. Da arquitectura do sítio à arquitectura de um território João Muralha Cardoso

925 Estudo zooarqueológico das faunas do Calcolítico final de Vila Nova de São Pedro (Azambuja, Portugal): Campanhas de 2017 e 2018 Cleia Detry / Ana Catarina Francisco / Mariana Diniz / Andrea Martins / César Neves / José Morais Arnaud

943 As faunas depositadas no Museu Arqueológico do Carmo provenientes de Vila Nova de São Pedro (Azambuja): as campanhas de 1937 a 1967 Ana Catarina Francisco / Cleia Detry / César Neves / Andrea Martins / Mariana Diniz / José Morais Arnaud

959 Análise funcional de material lítico em sílex do castro de Vila Nova de S. Pedro (Azambuja, Portugal): uma primeira abordagem Rafael Lima

971 O recinto da Folha do Ouro 1 (Serpa) no contexto dos recintos de fossos calcolíticos alentejanos

António Carlos Valera / Tiago do Pereiro / Pedro Valério / António M. Monge Soares

\section{Proto-História}

987 Produção de sal marinho na Idade do Bronze do noroeste Português. Alguns dados para uma reflexão

Ana M. S. Bettencourt / Sara Luz / Nuno Oliveira / Pedro P. Simões / Maria Isabel C. Alves / Emílio Abad-Vidal

1001 A estátua-menir do Pedrão ou de São Bartolomeu do Mar (Esposende, noroeste de Portugal) no contexto arqueológico da fachada costeira de entre os rios Neiva e Cávado Ana M. S. Bettencourt / Manuel Santos-Estévez / Pedro Pimenta Simões / Luís Gonçalves

1015 O Castro do Muro (Vandoma/Baltar, Paredes) - notas para uma biografia de ocupação da Idade do Bronze à Idade Média

Maria Antónia D. Silva / Ana M. S. Bettencourt / António Manuel S. P. Silva / Natália Félix

1031 Do Bronze Final à Idade Média - continuidades e hiatos na ocupação de Povoados em Oliveira de Azeméis João Tiago Tavares / Adriaan de Man

1041 As faunas do final da Idade do Bronze no Sul de Portugal: leituras desde o Outeiro do Circo (Beja)

Nelson J. Almeida / Íris Dias / Cleia Detry / Eduardo Porfírio / Miguel Serra

1055 A Espada do Monte das Oliveiras (Serpa) - uma arma do Bronze Pleno do Sudoeste Rui M. G. Monge Soares / Pedro Valério / Mariana Nabais / António M. Monge Soares

1065 São Julião da Branca (Albergaria-a-Velha) - Investigação e valorização de um povoado do Bronze Final

António Manuel S. P. Silva / Paulo A. P. Lemos / Sara Almeida e Silva / Edite Martins de Sá

1083 Do castro de S. João ao Mosteiro de Santa Clara: notícia de uma intervenção arqueológica, em Vila do Conde Rui Pinheiro 
1095 O castro de Ovil (Espinho), um quarto de século de investigação - resultados e questões em aberto

Jorge Fernando Salvador / António Manuel S. P. Silva

1111 O Castro de Salreu (Estarreja), um povoado proto-histórico no litoral do Entre Douro e Vouga

Sara Almeida e Silva / António Manuel S. P. Silva / Paulo A. P. Lemos / Edite Martins de Sá

1127 Castro de Nossa Senhora das Necessidades (Sernancelhe): uma primeira análise artefactual Telma Susana O. Ribeiro

${ }_{1141}$ A cividade de Bagunte. O estado atual da investigação Pedro Brochado de Almeida

1153 Zoomorfos na cerâmica da Idade do Ferro no NW Peninsular: inventário, cronologias e significado Nuno Oliveira / Cristina Seoane

1163 Vasos gregos em Portugal: diferentes maneiras de contar a história do intercâmbio cultural na Idade do Ferro

Daniela Ferreira

1175 Os exotica da necrópole da Idade do Ferro do Olival do Senhor dos Mártires (Alcácer do Sal) no seu contexto regional

Francisco B. Gomes

\section{Antiguidade Clássica e Tardia}

1191 O uso de madeira como combustível no sítio da Quinta de Crestelos (Baixo Sabor): da Idade do Ferro à Romanização Filipe Vaz / João Tereso / Sérgio Simões Pereira / José Sastre / Javier Larrazabal Galarza / Susana Cosme / José António Pereira / Israel Espi

1207 Cultivos de Época Romana no Baixo Sabor: continuidade em tempos de mudança? João Pedro Tereso / Sérgio Simões Pereira / Filipe Santos / Luís Seabra / Filipe Vaz

1221 A casa romana na Hispânia: aplicação dos modelos itálicos nas províncias ibéricas Fernanda Magalhães / Diego Machado / Manuela Martins

1235 As pinturas murais romanas da Rua General Sousa Machado, n. ${ }^{5}$ 1, Chaves José Carvalho

1243 Trás do Castelo (Vale de Mir, Pegarinhos, Alijó) - Uma exploração agrícola romana do Douro

Tony Silvino / Pedro Pereira

1255 A sequência de ocupação no quadrante sudeste de Bracara Augusta: as transformações de uma unidade doméstica Lara Fernandes / Manuela Martins

1263 Os Mosaicos com decoração geométrica e geométrico-vegetalista dos sítios arqueológicos da área do Conuentus Bracaraugustanus. Novas abordagens quanto à conservação, restauro, decoração e datação Maria de Fátima Abraços / Licínia Wrench

1277 “Casa Romana” do Castro de São Domingos (Cristelos, Lousada): Escavação, Estudo e Musealização Paulo André de P. Lemos

1291 A arqueobotânica no Castro de Guifões (Matosinhos, Noroeste de Portugal): O primeiro estudo carpológico

Luís Seabra / Andreia Arezes / Catarina Magalhães / José Varela / João Pedro Tereso 
1305 Um Horreum Augustano na Foz do Douro (Monte do Castelo de Gaia, Vila Nova de Gaia) Rui Ramos

1311 Ponderais romanos na Lusitânia: padrões, formas, materiais e contextos de utilização Diego Barrios Rodríguez

1323 Um almofariz centro-itálico na foz do Mondego

Marco Penajoia

1335 Estruturas romanas de Carnide - Lisboa Luísa Batalha / Mário Monteiro / Guilherme Cardoso

1347 O contexto funerário do sector da "necrópole NO" da Rua das Portas de S. Antão (Lisboa): o espaço, os artefactos, os indivíduos e a sua interconectividade na interpretação do passado Sílvia Loja, José Carlos Quaresma, Nelson Cabaço, Marina Lourenço, Sílvia Casimiro, Rodrigo Banha da Silva, Francisca Alves-Cardoso

${ }_{1361}$ Povoamento em época Romana na Amadora - resultados de um projeto pluridisciplinar Gisela Encarnação / Vanessa Dias

1371 A Arquitectura Residencial em Mirobriga (Santiago do Cacém): contributo a partir de um estudo de caso Filipe Sousa / Catarina Felício

${ }_{1385}$ O fim do ciclo. Saneamento e gestão de resíduos nos edifícios termais de Mirobriga (Santiago do Cacém)

Catarina Felício / Filipe Sousa

1399 Balsa, Topografia e Urbanismo de uma Cidade Portuária Vítor Silva Dias / João Pedro Bernardes / Celso Candeias / Cristina Tété Garcia

1413 No Largo das Mouras Velhas em Faro (2017): novas evidências da necrópole norte de Ossonoba e da sua ocupação medieval Ricardo Costeira da Silva / Paulo Botelho / Fernando Santos / Liliana Nunes

1429 Instrumentos de pesca recuperados numa fábrica de salga em Ossonoba (Faro) Inês Rasteiro / Ricardo Costeira da Silva / Paulo Botelho

1439 A Necrópole Romana do Eirô, Duas Igrejas (Penafiel): intervenção arqueológica de 2016 Laura Sousa / Teresa Soeiro

1457 Ritual, descarte ou afetividade? A presença de Canis lupus familiaris na Necrópole Noroeste de Olisipo (Lisboa)

Beatriz Calapez Santos / Sofia Simões Pereira / Rodrigo Banha da Silva / Sílvia Casimiro / Cleia Detry / Francisca Alves Cardoso

1467 Dinâmicas económicas em Bracara na Antiguidade Tardia Diego Machado / Manuela Martins / Fernanda Magalhães / Natália Botica

1479 Cerâmicas e Vidros da Antiguidade Tardia do Edifício sob a Igreja do Bom Jesus (Vila Nova de Gaia) Joaquim Filipe Ramos

1493 Novos contributos para a topografia histórica de Mértola no período romano e na Antiguidade Tardia Virgílio Lopes

\section{8. Época Medieval}

1511 Cerâmicas islâmicas no Garb setentrional "português": algumas evidências e incógnitas Constança dos Santos / Helena Catarino / Susana Gómez / Maria José Gonçalves / Isabel Inácio / Gonçalo Lopes / Jacinta Bugalhão / Sandra Cavaco / Jaquelina Covaneiro / Isabel Cristina Fernandes / Ana Sofia Gomes 
1525 Contributo para o conhecimento da cosmética islâmica, em Silves, durante a Idade Média Rosa Varela Gomes

1537 Yábura e o seu território - uma análise histórico-arqueológica de Évora entre os séculos VIII-XII José Rui Santos

1547 A encosta sul do Castelo de Palmela - resultados preliminares da escavação arqueológica Luís Filipe Pereira / Michelle Teixeira Santos

1559 A igreja de São Lourenço (Mouraria, Lisboa): um conjunto de silos e de cerâmica medieval islâmica

Andreia Filipa Moreira Rodrigues

1571 O registo material de movimentações populacionais no Médio Tejo, durante os séculos XII-XIII. Dois casos de "sunken featured buildings", nos concelhos de Cartaxo e Torres Novas Marco Liberato / Helena Santos / Nuno Santos

1585 O nordeste transmontano nos alvores da Idade média. Notas para reflexão Ana Maria da Costa Oliveira

1601 Sepulturas escavadas na rocha do Norte de Portugal e do Vale do Douro: primeiros resultados do Projecto SER-NPVD

Mário Jorge Barroca / César Guedes / Andreia Arezes / Ana Maria Oliveira

1619 "Portucalem Castrum Novum" entre o Mediterrâneo e o Atlântico: o estudo dos materiais cerâmicos alto-medievais do arqueossítio da rua de D. Hugo, nํ. 5 (Porto) João Luís Veloso

1627 A Alta Idade Média na fronteira de Lafões: notas preliminares sobre a Arqueologia no Concelho de Vouzela

Manuel Luís Real / Catarina Tente

1641 Um conjunto cerâmico medieval fora de portas: um breve testemunho aveirense Susana Temudo

${ }_{1651}$ Os Lóios do Porto: uma perspetiva integrada no panorama funerário da Baixa Idade Média à Época Moderna em meios urbanos em Portugal

Ana Lema Seabra

1659 O Caminho Português Interior de Santiago como eixo viário na Idade Média Pedro Azevedo

1665 Morfologia Urbana: Um exercício em torno do Castelo de Ourém André Donas-Botto / Jaqueline Pereira

1677 Intervenção arqueológica na Rua Marquês de Pombal/Largo do Espírito Santo (Bucelas, Loures)

Florbela Estêvão / Nathalie Antunes-Ferreira / Dário Ramos Neves / Inês Lisboa

1691 O Cemitério Medieval do Poço do Borratém e a espacialidade funerária na cidade de Lisboa Inês Belém / Vanessa Filipe / Vasco Noronha Vieira / Sónia Ferro / Rodrigo Banha da Silva

1705 Um Espaço Funerário Conventual do séc. XV em Lisboa: o caso do Convento de São Domingos da Cidade Sérgio Pedroso / Sílvia Casimiro / Rodrigo Banha da Silva / Francisca Alves Cardoso

\section{9. Época Moderna e Contemporânea}

1721 Arqueologia Moderna em Portugal: algumas reflexões críticas em torno da quantificação de conjuntos cerâmicos e suas inferências históricas e antropológicas Rodrigo Banha da Silva / André Bargão / Sara da Cruz Ferreira

1733 Faianças de dois contextos entre os finais do século XVI e XVIII do Palácio dos Condes de Penafiel, Lisboa

Martim Lopes / Tomás Mesquita 
1747 Um perfil de consumo do século XVIII na foz do Tejo: O caso do Mercado da Ribeira, Lisboa Sara da Cruz Ferreira / Rodrigo Banha da Silva / André Bargão

1761 Os Cachimbos dos Séculos XVII e XVIII do Palácio Mesquitela e Convento dos Inglesinhos (Lisboa)

Inês Simão / Marina Pinto / João Pimenta / Sara da Cruz Ferreira / André Bargão / Rodrigo Banha da Silva

1775 "Tomar os fumos da erua que chamão em Portugal erua sancta». Estudo de Cachimbos provenientes da Rua do Terreiro do Trigo, Lisboa

Miguel Martins de Sousa / José Pedro Henriques / Vanessa Galiza Filipe

1787 Cachimbos de Barro Caulínitico da Sé da Cidade Velha (República de Cabo Verde)

Rodrigo Banha da Silva / João Pimenta / Clementino Amaro

1801 Algumas considerações sobre espólio não cerâmico recuperado no Largo de Jesus (Lisboa) Carlos Boavida

1815 Adereços de vidro, dos séculos XVI-XVIII, procedentes do antigo Convento de Santana de Lisboa (anéis, braceletes e contas)

Joana Gonçalves / Rosa Varela Gomes / Mário Varela Gomes

1837 Da ostentação, luxo e poder à simplicidade do uso quotidiano: arqueologia e simbologia de joias e adornos da Idade Moderna Portuguesa Jéssica Iglésias

1849 Os amuletos em Portugal - dos objetos às superstições: o coral vermelho Alexandra Vieira

1865 Cerâmicas de Vila Franca de Xira nos séculos XV e XVI Eva Pires

1879 «Não passa por teu o que me pertence». Marcas de individualização associadas a faianças do Convento de Nossa Senhora de Aracoeli, Alcácer do Sal Catarina Parreira / Íris Fragoso / Miguel Martins de Sousa

1891 Cerâmica de Leiria: alguns focos de produção

Jaqueline Pereira / André Donas-Botto

1901 Os Fornos na Rua da Biquinha, em Óbidos Hugo Silva / Filipe Oliveira

1909 A casa de Pêro Fernandes, contador dos contos de D. Manuel I: o sítio arqueológico da Silha do Alferes, Seixal (século XVI) Mariana Nunes Ferreira

1921 O Alto da Vigia (Sintra) e a vigilância e defesa da costa Alexandre Gonçalves / Sandra Santos

1937 O contexto da torre sineira da Igreja de Santa Maria de Loures Paulo Calaveira / Martim Lopes

1949 A Necrópole do Hospital Militar do Castelo de São Jorge e as práticas funerárias na Lisboa de Época Moderna Susana Henriques / Liliana Matias de Carvalho / Ana Amarante / Sofia N. Wasterlain

1963 SAND - Sarilhos Grandes Entre dois Mundos: o adro da Igreja e a Paleobiologia dos ossos humanos recuperados

Paula Alves Pereira / Roger Lee Jesus / Bruno M. Magalhães

1975 Expansão urbana da vila de Cascais no século XVII e XVIII: a intervenção arqueológica na Rua da Vitória no 15 a 17

Tiago Pereira / Vanessa Filipe

1987 Novos dados para o conhecimento do Urbanismo de Faro em época Moderna Ana Rosa 
1995 Um exemplo de Arqueologia Urbana em Alcoutim: o Antigo Edifício dos CTT Marco Fernandes / Marta Dias / Alexandra Gradim / Virgílio Lopes / Susana Gómez Martínez

2007 Palácio dos Ferrazes (Rua das Flores/Rua da Vitória, Porto): a cocheira de Domingos Oliveira Maia

Francisco Raimundo

2021 As muitas vidas de um edifício urbano: História, Arqueologia e Antropologia no antigo Recreatório Paroquial de Penafiel Helena Bernardo / Jorge Sampaio / Marta Borges

2035 O convento de Nossa Senhora da Esperança de Ponta Delgada: o contributo da arqueologia para o conhecimento de um monumento identitário João Gonçalves Araújo / N’Zinga Oliveira

2047 Arqueologia na ilha do Corvo... em busca da capela de Nossa Senhora do Rosário Tânia Manuel Casimiro / José Luís Neto / Luís Borges / Pedro Parreira

2059 Perdidos à vista da Costa. Trabalhos arqueológicos subaquáticos na Barra do Tejo Jorge Freire / José Bettencourt / Augusto Salgado

2071 Arqueologia marítima em Cabo Verde: enquadramento e primeiros resultados do projecto CONCHA

José Bettencourt / Adilson Dias / Carlos Lima / Christelle Chouzenoux / Cristóvão Fonseca / Dúnia Pereira / Gonçalo Lopes / Inês Coelho / Jaylson Monteiro / José Lima / Maria Eugénia Alves / Patrícia Carvalho / Tiago Silva

2085 Trabalhos arqueológicos na Cidade Velha (Ribeira Grande de Santiago, Cabo Verde): reflexões sobre um projecto de investigação e divulgação patrimonial André Teixeira / Jaylson Monteiro / Mariana Mateus / Nireide Tavares / Cristovão Fonseca / Gonçalo C. Lopes / Joana Bento Torres / Dúnia Pereira / André Bargão / Aurélie Mayer / Bruno Zélie / Carlos Lima / Christelle Chouzenoux / Inês Henriques / Inês Pinto Coelho / José Lima / Patrícia Carvalho / Tiago Silva

2103 A antiga fortificação de Quelba / Khor Kalba (E.A.U.). Resultados de quatro campanhas de escavações, problemáticas e perspectivas futuras Rui Carita / Rosa Varela Gomes / Mário Varela Gomes / Kamyar Kamyad

2123 Colónias para homens novos: arqueologia da colonização agrária fascista no noroeste ibérico Xurxo Ayán Vila / José Mạ . Señorán Martín 


\title{
ESTUDO ZOOARQUEOLÓGICO DAS FAUNAS DO CALCOLÍTICO FINAL DE VILA NOVA DE SÃO PEDRO (AZAMBUJA, PORTUGAL): CAMPANHAS DE 2017 E 2018
}

Cleia Detry ${ }^{1}$, Ana Catarina Francisco ${ }^{2}$, Mariana Diniz ${ }^{1,3}$, Andrea Martins ${ }^{1,3,4}$, César Neves ${ }^{1,3}$, José Morais Arnaud ${ }^{1,3}$

\begin{abstract}
RESUMO
Em 2017, uma equipa da UNIARQ - Faculdade de Letras da Universidade de Lisboa e da Associação dos Arqueólogos Portugueses apresentou, à Direcção Geral do Património Cultural, um projecto de investigação intitulado Vila Nova de São Pedro, de novo no $3^{\circ}$ milénio (VNSP3ooo), com a intenção de retomar as escavações em VNSP. No âmbito de um seminário de Licenciatura em Arqueologia na FLUL, Ana Costa Francisco analisou os restos recuperados na primeira campanha de 2017. As faunas recuperadas nas campanhas seguintes foram estudadas por Cleia Detry.

Os restos de fauna doméstica demonstram a presença de ovelha/cabra (Ovis/Capra), vaca (Bos taurus) e porco (Sus scrofa domesticus). A caça também tem uma prevalência elevada com a presença de coelho (Oryctolagus cuniculus) e veado (Cervus elaphus). O auroque (Bos primigenius) e javali (Sus scrofa), embora difíceis de distinguir dos seus congéneres domesticados, foram identificados no conjunto.

Palavras-chave: Zooarqueologia, Calcolítico, Vila Nova de São Pedro.
\end{abstract}

\begin{abstract}
In 2017, a team from UNIARQ - School of Arts and Humanities of the University of Lisbon and the Association of Portuguese Archaeologists presented a research project to the Directorate-General for Cultural Heritage, entitled Vila Nova de São Pedro in the $3^{\text {rd }}$ millennium (VNSP3ooo), with the intention to resume excavations in VNSP. Within the scope of a seminar of the Degree in Archaeology at the School of Arts and Humanities of the University of Lisbon, Ana Costa Francisco, analysed the remains recovered in the first campaign of 2017. The fauna recovered in the following campaigns were studied by Cleia Detry.

The remains of domestic fauna demonstrate the presence of sheep/goat (Ovis/Capra), cattle (Bos taurus) and pig (Sus scrofa domesticus). Hunting is also highly prevalent with the presence of rabbit (Oryctolagus cuniculus) and red deer (Cervus elaphus). The auroch (Bos primigenius) and wild boar (Sus scrofa), although difficult to distinguish from their domesticated counterparts, were also identified in the assemblage.

Keywords: Zooarchaeology, Chalcolithic, Vila Nova de São Pedro.
\end{abstract}

\section{INTRODUÇÃO}

Vila Nova de São Pedro (VNSP) é um icónico povoado calcolítico da Estremadura Portuguesa, caracterizado pelas suas três linhas de muralha e intervencionado entre 1937 e 1967 por Eugénio Jalhay (até
1950) e Afonso do Paço, com o apoio, entre outras instituições, da Associação dos Arqueólogos Portugueses (Arnaud e Gonçalves 1990; 1995) (Figura 1). $\mathrm{Na}$ década de 8o, decorreram duas campanhas de escavação estando os resultados sucintamente publicados (Gonçalves, 1987; 1994), permanecendo o

1. UNIARQ, Centro de Arqueologia da Universidade de Lisboa, Faculdade de Letras da Universidade de Lisboa; cdetry@gmail.com; m.diniz@letras.ulisboa.pt

2. Aluna de Mestrado da Universidade do Algarve; afrancisco1@campus.ul.pt

3. Associação dos Arqueólogos Portugueses; c.augustoneves@gmail.com; direccao@arqueologos.pt

4. Fundação para a Ciência e a Tecnologia; andrea.arte@gmail.com 
sítio durante as três décadas seguintes afastado dos cenários da investigação arqueológica.

Em 2016, investigadores da UNIARQ - FLUL e a Associação dos Arqueólogos Portugueses (AAP) iniciaram um projecto de investigação para o povoado calcolítico de Vila Nova de São Pedro (Azambuja, Portugal) intitulado "Vila Nova de São Pedro, de novo no $3^{\circ}$ milénio - VNSP3ooo" (Arnaud et al, 2017), tendo realizado, sucessivas campanhas de terreno em 2017, 2018 e 2019 (Martins et al, 2019).

Relativamente aos restos faunísticos recolhidos neste povoado foram estudados os materiais das campanhas de A. Paço (Francisco et al, neste volume), existindo ainda um estudo não publicado de Elisabeth Wright sobre as faunas recuperadas nas escavações de 1985/86 (Wright in press).

Apresentamos neste artigo o estudo da fauna de uma unidade estratigráfica específica, identificada nas campanhas de 2017 e 2018, no âmbito do projecto VNSP30oo. A interpretação dos dados possibilitou a comparação com os sítios arqueológicos da Estremadura portuguesa, também de cronologia calcolítica, como Columbeira, Zambujal, Penedo do Lexim e Leceia.

\section{O CONTEXTO ARQUEOLÓGICO - VNSP A3 - UNIDADE ESTRATIGRÁFICA 305}

$\mathrm{Na}$ primeira campanha de campo do projeto VNSP3Ooo, teve início a escavação de uma área designada como Sondagem 1 - Área 3, que tinha como objectivo a caracterização de uma área a Este do recinto central, marcada por um talude artificial de cerca de 4 metros de altura que poderia corresponder à extensão para este sector da segunda linha de muralha (Martins et al, 2019: 143) (Figura 2).

Na plataforma inferior do talude identificou-se uma unidade sedimentar assente nos calcários de base, [305] cujas características são as seguintes:

[305] - Unidade sedimentar de matriz humosa-arenosa, muito homogénea na sua composição, muito orgânica, de coloração castanha-escura solta, com algumas zonas semi-compactas, com abundantes elementos pétreos de calcário de pequena e média dimensão e abundantes raízes. Na base da vertente criada por este talude - portanto já na plataforma inferior, esta UE cobre a rocha de base tendo surgido na área central da escavação grandes blocos pétreos de calcário, que se encontravam solidamen- te imbrincados e que colmatavam, artificialmente, a entrada de um pequeno algar (Figura 3).

A [305] representa a um nível arqueológico bem definido do ponto de vista sedimentar que corresponde às fases de ocupação terminal do sítio arqueológico. Este horizonte pedológico de reduzida potência com uma espessura da ordem dos 30-40 $\mathrm{cm}$, apresenta sinais de bioturbação, provocada fundamentalmente por raízes, ao mesmo tempo que as características do substrato fazem com que os materiais arqueológicos fiquem depositados (e preservados) nas fissuras do lapiás. Não foram identificadas estruturas antrópicas, existindo no entanto abundante material arqueológico: cerâmica manual lisa (formas abertas e fechadas, taças, pratos de bordo espessado), cerâmica manual decorada (decoração "crucífera" e campaniforme), indústria lítica maioritariamente em sílex (além de restos de talhe, lamelas e lascas, destacam-se os utensílios retocados como as pontas de seta, foliáceos e furadores), fragmentos de ídolos de cornos, vários fragmentos de placas/pesos de tear e fragmentos de queijeiras (Martins et al, 2019: 156). Surgem abundantes restos de fauna mamalógica muito fragmentada e erodida e alguma fauna malacológica.

Conforme publicado (Martins et al, 2019: 156) foram efectuadas três datações por $\mathrm{Cl}_{4}$, sobre fauna mamalógica (Cervus elaphus, Sus sp. e Bos sp.), recolhida nesta unidade cujos resultados permitem situar este nível nos meados do $3^{\circ}$ quartel do $3^{\circ}$ milénio (2577-2297 cal BC), incorporando esta algum material mais tardio, datado do $2^{\circ}$ quartel do $2^{\circ}$ milénio cal $\mathrm{BC}$, claramente intrusivo num ambiente cronológica e artefactualmente próprio do Calcolítico pleno.

\section{METODOLOGIA DE ESCAVAÇÃO E DE ANÁLISE DOS RESTOS FAUNÍSTICOS}

Os trabalhos de campo realizados no âmbito do projecto VNSP3ooo obedeceram a uma metodologia de recolha de dados em campo substantivamente distinta da utilizada nas escavações dos anos 30-6o, como já referido neste volume (Francisco et al.). Nos trabalhos agora realizados, todo o sedimento escavado - à excepção da camada superficial de manta morta - foi crivado em crivo seco com malha de $3 \mathrm{~mm}$ de lado e todos os restos faunísticos recolhidos.

Todos os ossos, dentes e conchas, recuperados na 
escavação da unidade estratigráfica [305], durante as campanhas de 2017 e 2018 , foram registados e contabilizados.

Em relação aos elementos osteológicos, quando possível, cada um foi identificado morfologicamente e taxonomicamente. Quando uma identificação taxonómica não foi possível, classificaram-se os elementos por critérios de tamanho dos animais a que poderiam pertencer, classificando-os como macrofauna (grande porte), mesofauna (médio porte) e microfauna (pequeno porte). São considerados animais de grande porte todo o gado bovino, os equídeos e o veado. Os de tamanho médio são animais como os caprinos ou suínos e os de pequeno porte são os coelhos ou animais mais pequenos.

Os dentes foram contabilizados e classificados da mesma maneira. Com este registo, foi obtido o Número de Restos (NR), isto é o total de restos contabilizados. O Número de Restos Determinados (NRD) contabilizou os que foram determinados taxonomicamente, tal como definido por Valente (1997). Para calcular o Número Mínimo de Indivíduos (NMI), registou-se ainda o Número Mínimo de Elementos (NME), recorrendo ao método de registo dos POSAC's (Parts of the Skeleton Always Counted) de Davis (1992).

A identificação taxonómica foi realizada com a ajuda da colecção de referência da UNIARQ e, em casos mais difíceis, complementada com a colecção de referência do Laboratório de Arqueociências da Direcção Geral do Património Cultural (LARC-DGPC). Para estabelecer perfis de idade à data da morte e ajudar no cálculo do NMI, foi registado o estado de fusão dos ossos: Fundido, no caso de a epífise estar completamente fundida à diáfise; Metáfise não fundida; Epífise não fundida; e ainda Fusão visível nos casos em que esta não estava completa. Com o mesmo objectivo, o de observar a idade, registámos o desgaste dos dentes dos animais domésticos usando para o efeito a escala de Grant (1982), para os suínos e bovinos e a de Payne (1987), para os caprinos.

Foram ainda registados dados que nos podem dar alguma informação tafonómica, nomeadamente a presença de marcas de corte, de fogo ou da acção de carnívoros ou roedores sobre os ossos. A influência de outros agentes como raízes ou erosão natural foram também interpretados e registados.

Os raros ossos e dentes completos foram medidos para identificar o estatuto selvagem ou doméstico do animal, no caso dos bovinos e suínos. Para isso utilizou-se uma craveira digital com erro inferior a o,1 $\mathrm{mm}$ e foram seguidos os critérios definidos por Driesch (1976).

\section{RESULTADOS E DISCUSSÃO}

Dos restos osteológicos analisados para este estudo, 2419 não foram determinados ao nível taxonómico. Com efeito, $63 \%$ dos restos eram fragmentos demasiado pequenos e/ou incaracterísticos para permitir estabelecer a sua relação com alguma das espécies conhecidas (ver Tabela 1). Em $27 \%$ da amostra foi possível a identificação por grupos de tamanho, mostrando uma preponderância da fauna de médio porte, em concordância com a prevalência das espécies que foram identificadas.

Os vestígios osteológicos obtidos nestas escavações apresentam-se, em geral, muito fragmentados e alvo de erosão acentuada - provocada por uma exposição aérea longa antes da sua cobertura pelos sedimentos que darão origem a esta UE - o que explica, em grande medida, a percentagem muito reduzida de ossos identificados taxonomicamente (10\%).

Os restos de invertebrados (gastrópodes e bivalves) são vestigiais neste conjunto. Existindo 11 restos de gastrópodes terrestres que podem corresponder a animais intrusivos já que ocorrem naturalmente em contextos com humidade e matéria orgânica. Bem como uns poucos restos (cinco fragmentos de concha) de uma única espécie de bivalve, a ameijoa (Ruditapes decussatus). Esta espécie terá de ter sido trazida da orla marítima já que não tolera salinidades muito baixas e precisa de ambiente arenoso própria de contexto marinho, eventualmente de estuário. Estes restos são compatíveis com os apresentados por Francisco et al. (2020, neste volume), para as escavações de Afonso do Paço no mesmo sítio.

Não foram encontrados restos de peixe ou anfíbios apesar da cuidadosa crivagem desta unidade estratigráfica. Estes restos poderão exigir protocolos de flutuação de sedimentos específicos a desenvolver em futuras intervenções.

\subsection{Espécies}

As espécies identificadas na [305] são na sua grande maioria de vertebrados e pertencentes a aves e mamíferos. A diversidade de animais selvagens é também bastante elevada quando comparada com 
outros estudos realizados em sítios do mesmo período cronológico.

Em relação aos restos de aves, apenas quatro ossos foram atribuídos a este grupo e apenas dois identificados como Alectoris rufa (perdiz-vermelha), um pequeno galiforme selvagem ainda hoje muito frequente na fauna portuguesa.

Os mamíferos dominam assim os restos encontrados, com a presença de espécies domésticas e selvagens. Dos 144 restos de mamíferos identificados taxonomicamente temos, desde já, três espécies raras em contextos arqueológicos, mas que aparecem em Vila Nova de São Pedro (tabelas 2 e 3).

A mais rara será o castor (Castor fiber), uma espécie actualmente extinta na Península Ibérica e que possivelmente terá desaparecido no séc. XV (Antunes, 1989). Esta foi ainda encontrada no Baixo Sabor, em contextos romanos (Detry et al., 2015), e na gruta do Caldeirão e Almonda nos níveis Paleolíticos (Antunes, 1989). Sendo uma espécie dependente dos cursos de água, terá provavelmente sido capturada nas bacias hidrográficas circundantes. Foi encontrada apenas parte de uma pélvis (Figura 4), e sem marcas de corte pelo que não conseguimos comprovar o seu consumo, mas a sua pele e o seu conhecido castoreum (substância perfumada de origem glandular), são produtos muito apreciados desde a Antiguidade. Já Afonso do Paço refere na sua lista de espécies encontradas em Vila Nova de São Pedro, a presença de castor (Paço, 1958).

Outra espécie de muito interesse, mas representada apenas por um metacarpo muito bem preservado é o urso-pardo (Ursus arctos) (Figura 5). A presença de elementos osteológicos da pata não garante a presença de um animal inteiro já que muitas vezes ao extrair-se a pele destes animais se conservavam as patas ou até mesmo o crânio. A referência de Paço e Jalhay a restos de urso, pelo menos dois animais de distintas dimensões (1943: 21 in Francisco et al., este volume), é agora confirmada.

A pele deste animal seria muito apreciada e o consumo da sua carne foi já atestado em muitos contextos (eg. Detry e Arruda, 2013, Fernandes et al. 2012), incluindo em Leceia (Pires et al. 2002).

Esta espécie terá sido relativamente frequente (para um grande carnívoro) e ter-se-á extinguido em Portugal no séc. XIX. O urso voltou a reaparecer nos últimos anos com pequenas intrusões de animais vindos de Espanha em virtude, provavelmente, do abandono rural e consequente melhoramento do habitat. Ora, esta espécie depende de zonas florestais e evitaria povoações. Os humanos competiriam na caça das mesmas presas o que terá determinado também a sua extinção. No Calcolítico poderiam estar menos afectados por esta pressão e ser mais frequentes. Ainda assim, um grande carnívoro deste tipo seria difícil de caçar.

Por fim, ainda dentro das espécies raras temos o lince-ibérico (Lynx pardinus), com quatro elementos: dois astrágalos, um calcâneo e uma falange I distal, partes que podem pertencer a um único animal. Esta espécie, hoje presente apenas no Sul de Portugal e com problemas de conservação graves, terá existido de Norte a Sul do país. Com efeito, há elementos desta espécie em vários contextos arqueológicos, quer pré-históricos como em Muge, no Mesolítico (Detry, 2007), quer em contextos de cronologias mais recentes, como no Baixo Sabor (Castelinho e Cemitério dos Mouros, Detry et al., 2015), ou em Lagos, na ocupação romana de Monte Molião (Detry e Arruda, 2013). Em Muge, as marcas de corte e de fogo, comprovam o seu consumo, ao contrário do caso de VNSP onde não se comprova nem se exclui o consumo deste animal. Dentro das espécies herbívoras com um número reduzido de elementos temos o corço (Capreolus capreolus), representado apenas por um molar superior. Esta espécie de pequeno cervídeo também terá sido frequente no passado, mas mais difícil de caçar que o veado e típica de ambiente florestal de estrato arbustivo desenvolvido. Aparece em números representativos nos concheiros mesolíticos de Muge (Detry, 2007), provável presença no povoado do Neolítico antigo da Valada do Mato (Valente in Diniz 2007), torna-se menos frequente em outros contextos pré-históricos como nos povoados calcolíticos de S. Pedro (Davis e Mataloto, 2012: 62), Castro da Columbeira (Correia, 2015:86) e Chibanes (Pereira et al, 2017: 5).

Um dente de equídeo é também o único elemento desta família podendo pertencer a cavalo ou burro (Equus caballus ou Equus asinus). Embora completo, não apresenta características passíveis de determinar a espécie, sendo mais provável que este elemento pertença a cavalo. O burro, cuja introdução foi frequentemente atribuída aos fenícios, tem a forte possibilidade de ter já existido anteriormente como demonstra o asinino encontrado no povoado calcolítico de Leceia (Cardoso et al. 2013), mas ainda assim são muito raros os seus restos em contextos pré-históricos. 
No caso do cavalo resta ainda a dúvida sobre o estatuto doméstico ou selvagem destes exemplares. O processo e a cronologia da domesticação do cavalo na Península Ibérica são ainda pouco claros já que também são poucas ou nenhumas as alterações morfológicas que permitam distinguir os equídeos selvagens dos domesticados.

Em sítios como Caseton de La Era (Valladolid, Espanha), com elevado número de equídeos, os zooarqueólogos tendem para a sua classificação como animais selvagens, confirmando-se a falta de provas sobre a presença de cavalo domesticado, na Península Ibérica, durante o Calcolítico (Araña, 2020).

Quanto aos grupos taxonómicos mais frequentes temos suídeos (porco e javali), bovinos (gado doméstico e auroque) e caprinos (ovelha e cabra). Este grupo de animais constitui cerca de 70\% dos restos de mamíferos identificados (ver tabela 1), sendo que, neste caso, poderemos ter um número relevante de restos de javali e auroque.

De facto, na figura 6 podemos observar que todos os astrágalos de Sus sp. apresentam medidas compatíveis com as do javali mesolítico dos concheiros de Muge (Detry, 2007). Já o único dente que foi possível medir, um terceiro molar inferior de Sus sp., apresentou medidas dentro do espectro do animal doméstico (L-3o,6 mm; Wa- 13,3mm; Wb$-14,3 \mathrm{~mm}$ ), quando comparadas com as referidas em Detry e Arruda (2013, fig. 5). É possível que os restos de suídeo recuperados na UE [305] pertençam, por isso, na sua maioria à espécie selvagem.

Quanto aos ossos de bovino, os astrágalos mensuráveis demonstram medidas dentro da amplitude da espécie doméstica (GLl-62,2mm; 62,6mm); veja-se as medidas referidas por Davis e Detry (2013, Fig. 5). Ao utilizarmos a largura proximal (Bp) de dois metacarpos de VNSP e comparando com as de Muge (Detry, 2007) vemos que uma se situa na margem inferior da amplitude (Bp-65,5mm) e a outra já se enquadra confortavelmente dentro do intervalo de medidas para o auroque (Bp-70,2mm). Enquanto a primeira, tendo em conta que os auroques no Mesolítico seriam mais pequenos do que no Calcolítico (Davis e Detry, 2013), se pode atribuir possivelmente ao animal doméstico, o segundo metacarpo de maiores proporções pertence seguramente a auroque.

$\mathrm{Na}$ figura 7, podemos observar uma tendência semelhante das duas falanges medidas: uma insere-se claramente nas medidas de auroque quando comparadas com as medidas de bovinos do Zambu- jal (Driesch e Boessneck, 1976), enquanto a outra, com medidas claramente inferiores, se enquadra na espécie doméstica.

Se pensarmos ter uma proporção de 1:1 de auroque $v s$. vaca em VNSP, é uma percentagem muito elevada de animais selvagens quando comparado com o Zambujal (Driesch e Boesseneck, 1976) ou Leceia (Cardoso e Detry, 2002). No entanto, atendendo à pequena dimensão do conjunto observado não é possível avançar para já com a reconstituição do peso da caça/pastorícia no quadro dos comportamentos de subsistência.

O veado e sobretudo o coelho-bravo constituem cerca de $24 \%$ da amostra de mamíferos, demonstrando mais uma vez a relevância da caça para estas populações.

Obtiveram-se poucas medidas, o que não nos permitiu confirmar a tese de Davis e Detry (2013) sobre o maior tamanho das espécies selvagens no Calcolítico. No entanto, os ossos medidos efectivamente não se apresentavam na franja inferior das medidas existentes, o que pelo menos não exclui a hipótese defendida por estes autores.

\subsection{Perfil de idades}

Em relação ao perfil de idades, pouco podemos avançar já que o número de ossos em que se podia observar a fusão era reduzido. Ainda assim, a grande maioria já se apresentava fundida e o único elemento não fundido pertence a Sus sp.

Em relação aos dentes de suídeos também o seu desgaste parecia reduzido e temos apenas a presença de dois dentes de leite de porco e dois de ovelha ou cabra. Temos igualmente a presença de animais mais velhos como sugerido pela existência de um terceiro molar inferior de Sus sp. e de um mesmo dente de ovelha, ou cabra, com o desgaste de $11 \mathrm{G}$, dentro da escala de desgaste de Payne (1987). Isso indicaria um animal de pelo menos 2 anos para o porco e de 4-6 anos para o caprino. Provavelmente seriam abatidos animais mais jovens para consumo da sua carne, bem como mantidos animais mais velhos para a reprodução (possivelmente o caso do porco) e produtos secundários (leite e lã) no caso da ovelha/cabra.

\subsection{Tafonomia}

Quanto à Tafonomia observaram-se quatro ossos com marcas de corte, três deles pertencentes a Bos sp. É possível que, tratando-se de um animal de maior porte, o desmanche produzisse mais marcas de corte, mas uma amostra reduzida como esta não 
nos permite grandes conclusões. As marcas de corte estão relacionadas com a remoção de pele (falanges, metacarpos e hastes/chifres) e desmembramento com objectivo de retirar a carne, peles e gorduras.

Apenas dois elementos não identificados taxonomicamente apresentavam marcas de fogo, o que representa uma percentagem muito reduzida, tal como já anotara A. Paço (in Francisco et al., este volume). Seis ossos apresentavam marcas de ter sido roídos por um carnívoro, mas não foi identificada, nesta UE, a presença de restos osteológicos do cão que provavelmente terá sido responsável por estas marcas, ficando assim a sua presença atestada indirectamente. Os ossos de um canídeo foram encontrados nas escavações antigas de VNSP (Idem, neste volume). Uma diáfise de tíbia apresentava marcas de roedor, constituindo um caso raro da utilização dos ossos pelos roedores para desgastarem os seus incisivos de crescimento contínuo (Figura 8). As marcas eram relativamente grandes podendo ser produzidas por animais como o rato-preto (Rattus rattus). Segundo Audoin-Rouzeau \& Vigne (1994: 132), terá sido introduzido no sul da Europa na Idade do Ferro e na Idade do Bronze - Boessneck et al. (1969) já refere elementos em Cerro del Real (Espanha). As marcas no osso podem ter sido feitas muito depois da ocupação do sítio, mas a serem contemporâneas de VNSP teriam sido feitas por um roedor mais pequeno e autóctone.

\subsection{Discussão dos dados}

Em suma, se observarmos, na Figura 9, e deste gráfico, excluímos os restos de coelho dado que estes podem ser bastante afectados pelo tipo de recolha em escavação, alterando de forma substantiva o quadro geral, a percentagem das quatro espécies mais frequentes em contextos arqueológicos calcolíticos da Estremadura Portuguesa (a norte do Tejo), podemos concluir que existe uma considerável diversidade, ao nível da exploração dos recursos faunísticos nos sítios estudados, com a excepção única do par porco/javali que é, em todos os sítios, excluindo VNSP[305], o segundo grupo de animais mais consumido. Numa leitura de conjunto, os valores percentuais da [305] de Vila Nova de São Pedro aproximam-se dos resultados obtidos no povoado do Zambujal, ao passo que Leceia, em particular no Calcolítico inicial, e o Penedo do Lexim parecem formar outro grupo. O sítio da Columbeira apresenta valores intermédios entre estes grupos.
O primeiro grupo - VNSP-[305] e Zambujal (Calcolítico Médio e Final) caracteriza-se pela elevada percentagem de vaca/auroque - cerca de $35 \%$ em ambos os sítios - logo seguida pelo peso do porco/ javali com valores que oscilam entre os c. de $40 \%$ em VNSP e $30 \%$ no Zambujal. Em ambos os casos a presença de animais inequivocamente domésticos - ovelha/cabra e inequivocamente selvagens - cervídeos - é claramente minoritária, comprometendo de forma óbvia uma leitura final acerca das espécies e das práticas dominantes nestes sítios.

O segundo grupo - Leceia (Calcolítico Inicial e Médio) e Penedo do Lexim têm como traços dominantes: a escassez, ou até ausência de animais de grande porte, - sejam eles domésticos ou selvagens (vaca, auroques e cervídeos); o peso muito expressivo da dupla ovelha/cabra que pode atingir $40 \% / 50 \%$ do conjunto, reflectindo de imediato o peso da pastorícia e por fim, numa estratégia centrada em animais de pequeno/médio porte, a importância da dupla porco/javali.

A relação pastorícia/caça em sítios onde são maioritários os grupos incertos - vaca/auroque e porco/ javali - se tem sido descrita como associada a uma economia produtora como no Zambujal (Driesch \& Boessneck), deixa em aberto, atendendo ao número significativo de auroques que parecem representados na pequena amostra da [305], o papel da caça nos ambientes da segunda metade do $3^{\circ}$ milénio (Davis e Mataloto, 2012).

No entanto, e qualquer que seja a relação pastorícia/ caça, as espécies selecionadas não são idênticas nos diferentes contextos - o par ovelha/cabra - fundamental nas economias de Leceia, Penedo do Lexim e Columbeira, parece menos significativo ou até marginal em VNSP ou Zambujal. Se a topografia acidentada da Columbeira ou do Penedo do Lexim podia explicar esta diferença expressiva face a VNSP/ Zambujal - ausência de bovinos e predilecção por ovelha/cabra - porco/javali, a integração do povoado de Leceia implantado no rebordo de uma vasta superfície aplanada, torna a explicação ambiental menos plausível.

\section{OBSERVAÇÕES FINAIS}

O presente trabalho permitiu estudar a fauna presente na unidade estratigráfica [305] da Área 3, Sondagem 1 , da intervenção realizada pelo projecto $\mathrm{VNSP}_{3} 000$. As análises taxonómica, osteométrica e tafonómica 
foram essenciais para a obtenção de informação sobre a economia alimentar no final da ocupação do sítio arqueológico de Vila Nova de São Pedro.

As campanhas de 2017 e 2018, proporcionaram registos faunísticos sistemáticos e contextualizados. A presença de espécies selvagens (Sus scrofa, Cervus elaphus, Bos primigenius, Oryctolagus cuniculus, Lynx pardinus, Castor fiber, Ursus arctos e Alectoris rufa) indica que a caça foi certamente uma atividade importante para as populações que viveram neste povoado calcolítico, revelando a especialização desta actividade face às características das espécies caçadas como o auroque, urso ou lince. A identificação de espécies domésticas (Ovis aries, Capra hircus, Sus scrofa domesticus e Bos taurus) demonstra também que estas populações dependiam igualmente de uma economia de pastorícia.

As datações obtidas para este contexto arqueológico específico mostram que a componente cinegética tem uma importância significativa no Calcolítico final, não apenas de espécies mais comuns como auroques, veados ou javalis, mas também lince, castor e urso, seguramente não apenas para consumo da carne, mas também para aproveitamento de peles. Neste período, e tendo em conta materiais arqueológicos também recolhidos neste mesmo contexto, o aproveitamento dos recursos secundários da pastorícia estaria certamente consolidado como é possível observar pelas queijeiras, bem como pelas placas de tear que, além da utilização fibras vegetais (como o linho identificado nas campanhas de A. Paço), poderiam utilizar lã. Apesar de raros, a idade avançada de alguns dos animais identificados revela-nos também esta opção de aproveitamento secundário e não apenas para consumo de carne.

Neste estudo pretendeu-se analisar um contexto específico, localizado numa área externa ao reduto central e " $2^{\underline{a}}$ linha" de muralha, não tendo sido aí identificadas estruturas domésticas. A preponderância de espécies selvagens poderá estar relacionada com uma área específica do povoado, separada da zona das espécies domesticadas que teriam estruturas de contenção (mais ou menos perecíveis) e áreas de abate e descarne de animais.

Tal como referido por A. Paço para algumas áreas do povoado (Paço, 1958) os ossos não apresentam vestígios de fogo podendo corresponder a processos de cozedura que não implicassem a acção directa do fogo.
Esta primeira abordagem ao estudo da fauna de um contexto datado de Vila Nova de São Pedro demonstra, por um lado, a consolidação do sistema agro-pastoril do $3^{\circ}$ milénio a.C., mas também, que a actividade cinegética continuou a fazer parte dos recursos sócio-económicos desta comunidade, tal como observado noutros povoados da Estremadura Portuguesa.

\section{AGRADECIMENTOS}

Ao Museu Arqueológico do Carmo e Associação dos Arqueólogos Portugueses pelo acesso aos materiais e disponibilização de meios e recursos para o presente estudo.

À UNIARQ - Centro de Arqueologia da Faculdade de Letras da Universidade de Lisboa pelas datações obtidas.

Ao Laboratório de Arqueociências da Direção Geral do Património a consulta da coleção de referência sendo uma ajuda essencial na identificação das espécies mais raras.

À Elizabeth Wright pela partilha dos seus dados não publicados sobre Vila Nova de São Pedro.

\section{BIBLIOGRAFIA}

ANTUNES, Miguel Teles (1989) - Castor fiber na gruta do Caldeirão Existência, distribuição e extinção do castor em Portugal. Ciências da Terra. 10, pp. 23-40.

ARAÑA, Maria (2020) - La gestión de los recursos ganaderos y cinegéticos durante la Prehistoria reciente en el Valle del Duero: El Casetón de la Era (Villalba de los Alcores, Valladolid) - Tese de Doutoramento. Universidad de Valladolid.

ARNAUD, José M.; GONCALVES, João Ludgero (1990) - A fortificação pré-histórica de Vila Nova de S., Pedro (Azambuja) - balanço de meio século de investigações. $1^{\underline{a}}$ parte. Revista de Arqueologia da Assembleia Distrital de Lisboa. 1. Lisboa, pp. 25-48.

ARNAUD, José M.; GONCALVES, João Ludgero (1995) - A fortificação pré-histórica de Vila Nova de S., Pedro (Azambuja) - balanço de meio século de investigações. $2^{\underline{a}}$ parte. Revista de Arqueologia da Assembleia Distrital de Lisboa. 2. Lisboa, pp. 11-40.

ARNAUD, José M.; DINIZ, Mariana; NEVES, César; MARTINS, Andrea (2017) - Vila Nova de São Pedro - de novo, no $3 .^{\circ}$ milénio. Um projecto para o futuro. Arqueologia e História, 66-67, Associação dos Arqueólogos Portugueses, Lisboa, pp. 7-17.

AUDOIN-ROUZEAU, Frédérique; VIGNE, Jean-Denis (1994) - La colonisation de l'Europe par le rat noir (Rattus rattus). Revue de paléobiologie, 13(1), pp. 125-145. 
BOESSNECK, Joachim; von den DRIESCH, Angela, SCHÜLE, Wilhelm, (1969) - Die Knochenfunde vom Cerrodel Real bei Galera (Prov. Granada); Die Fauna des "Cabezo Redondo" bei Villena (Prov. Alicante). In: Studien Über Frühe Tierknochenfunde von Der Iberischen Halbinsel. München Universitat, p. 106.

CARDOSO, João Luís; DETRY, Cleia (2002) - Estudo arqueozoológico dos restos de ungulados do povoado pré-histórico de Leceia (Oeiras). Estudos Arqueológicos de Oeiras. 10 , pp. 131-182.

CARDOSO, João Luís; VILSTRUP, Julia, EISENMANN, Vera; ORLANDO, Ludovico (2013) - First evidence of Equus asinus L. in the Chalcolithic disputes the Phoenicians as the first to introduce donkeys into the Iberian Peninsula. Journal of Archaeological Science, 40(12), p.4483-449o.

CORREIA, Francisco (2015) - O Castro da Columbeira (Bombarral): A Exploração dos Recursos Faunísticos no Calcolítico Estremenho. Tese de Mestrado UALG.

DAVIS, Simon (1992) - A rapid method for recording information about mammal bones from archaeological sites. London: Ancient Monuments Laboratory Ancient Monuments Laboratory Report; 19), pp. 1-14.

DAVIS, Simon; DETRY, Cleia (2013) - Crise no Mesolítico: Evidências Zooarqueológicas. ARNAUD, MARTINS e NEVES (coords.) - Arqueologia em Portugal - 150 Anos. Associação dos Arqueólogos Portugueses, Lisboa, pp. 297-309.

DAVIS, Simon, \& MATALOTO, Rui (2012) - Animal remains from Chalcolithic São Pedro (Redondo, Alentejo): evidence for a crisis in the Mesolithic. Revista Portuguesa de Arqueologia, 15(1), pp. 47-85.

DETRY, Cleia (2007) - Paleoecologia e Paleoeconomia do Baixo Vale do Tejo - Fauna Terrestre dos Concheiros de Muge. Tese de Doutoramento. Universidade de Salamanca.

DETRY, Cleia; ARRUDA, Ana Margarida (2013) - A fauna da Idade do Ferro e Época romana de Monte Molião (Lagos, Algarve): continuidades e rupturas na dieta alimentar. Revista Portuguesa de Arqueologia. Vol. 15: 215-227.

DETRY, Cleia, PEREIRA, Sérgio; DÓRDIO, Paulo (2015) - Estudo zooarqueológico dos materiais recuperados em Crestelos. Do Calcolítico ao Período Moderno. Relatório Final do estudo Zooarqueológico integrado no Plano de Salvaguarda do Património do Baixo Sabor.

DRIESCH, Angela von den (1976) - A guide to the measurement of animal bones from archaeological sites. Harvard: Harvard University, Peabody Museum of Archaeology and Ethnology.

DRIESCH, Angela von den; BOESSNECK, Joachim (1976) - Die fauna vom Castro do Zambujal. Studien über frühe Tierknochenfunde von der Iberischen Halbinsel. 5, pp. 4-129.
FAGES, A., Hanghøj, K., Khan, N., Gaunitz, C., SeguinOrlando, A., Leonardi, M.; Detry, Cleia; Alfarhan, A.H. (2019) - Tracking five millennia of horse management with extensive ancient genome time series. Cell.177(6), pp. 1419-1435.

FERNANDES, Isabel; CARDOSO, João Luís; DETRY, Cleia (2012) - Cozinhar e comer no Castelo Medieval de Palmela. In Susana Gómez Martinez (Ed). Memória dos sabores do Mediterrâneo. Campo Arqueológico de Mértola/ Centro de Estudos Arqueológicos de Coimbra e Porto, pp. 113-128.

FRANCISCO, Ana Catarina; DETRY, Cleia; NEVES, César; MARTINS, Andrea, DINIZ, Mariana; ARNAUD, José (2020) - As faunas depositadas no Museu Arqueológico do Carmo provenientes de Vila Nova de São Pedro (Azambuja): as campanhas de 1937 a 1967. ARNAUD, NEVES, MARTINS (Coord.) - Arqueologia em Portugal - 2020, estado da questão, Associação dos Arqueólogos Portugueses, Lisboa

GONÇALVES, Victor Santos (1987) - Trabalhos de campo. Distrito de Lisboa - Azambuja: Castelo de Vila Nova de São Pedro: 1985/86. Informação Arqueológica, Ministério da Cultura. Instituto Português do Património Cultural, Departamento de Arqueologia, no 8, pp. 41-43.

GONÇALVES, Victor Santos (1994) - O castelo de Vila Nova de S. Pedro. Lisboa Subterrânea. Lisboa: Electa, pp. 49-51.

GRANT, Annie (1982) - The use of tooth wear as a guide to the age of dome s tic ungulates. In B. Wilson, C. Grigson \& S. Payne, Ageing and sexing animal bones from Archaeological sites, Oxford: British Archaeological Reports - British series 109, pp. 91-108.

MARTINS, Andrea; NEVES, César; DINIZ, Mariana; ARNAUD, José (2019) - O povoado calcolítico de Vila Nova de São Pedro (Azambuja). Notas sobre as campanhas de escavação de 2017 e 2018. Arqueologia e História, nº 69, Associação dos Arqueólogos Portugueses, pp. 133-167.

PAÇO, Afonso do (1958) - Castro de Vila Nova de S. Pedro. X-Campanha de Escavações de 1956 (20aㅡ), Academia Portuguesa da História ANAIS, II série, vol.8, pp. 50-54.

PAYNE, Sebastian (1987) - Reference codes for wear states in the mandibular teeth of sheep and goats. Journal of Archaeological Science. Amsterdam, 14, pp. 609-614.

PEREIRA, Vera; SOARES, Joaquina; SILVA, Carlos Tavares (2017) - Understanding the First Chalcolithic Communities of Estremadura: Zooarchaeology of Castro de Chibanes, Portugal. Preliminary Results. Papers from the Institute of Archaeology, 27(1), pp. 1-11.

PIRES, Filipa; CARDOSO, João Luís; PETRUCCI-FONSECA, Francisco (2002) - Estudo Arqueozoológico dos carnívoros do povoado pré-histórico de Leceia (Oeiras). Estudos Arqueológicos de Oeiras, 10, pp. 183-247.

VALENTE, Maria João (1997) - A quantificação faunística: principais unidades, alguns parâmetros, regras e problemas. Estudos do Quaternário. Lisboa, 1, pp. 83-96. 


\begin{tabular}{|c|c|c|c|c|}
\hline & & & & \\
\hline & NRD & & NMI & \\
\hline & $\mathrm{N}$ & $\%$ & $\mathrm{~N}$ & $\%$ \\
\hline \multicolumn{5}{|l|}{ Mollusca } \\
\hline Gastropoda & 1 & $0,04 \%$ & 1 & $6 \%$ \\
\hline Cornu aspersa & 11 & $0,4 \%$ & 1 & $6 \%$ \\
\hline \multicolumn{5}{|l|}{ Bivalvia } \\
\hline Ruditapes decussata & 5 & $0,2 \%$ & 1 & $6 \%$ \\
\hline \multicolumn{5}{|l|}{ Vertebrata } \\
\hline \multicolumn{5}{|l|}{ Mammalia } \\
\hline Bos sp. (vaca e auroque) & 63 & $2 \%$ & 2 & $12 \%$ \\
\hline Ovis/Capra (ovelha/cabra) & 39 & $1 \%$ & 1 & $6 \%$ \\
\hline Sus sp. (porco e javali) & 89 & $3 \%$ & 2 & $12 \%$ \\
\hline Cervus elaphus (veado) & 15 & $1 \%$ & 1 & $6 \%$ \\
\hline Capreolus capreolus (corço) & 1 & $0,04 \%$ & 1 & $6 \%$ \\
\hline Equus sp. (cavalo e burro) & 2 & $0,1 \%$ & 1 & $6 \%$ \\
\hline Oryctolagus cuniculus (coelho) & 31 & $1 \%$ & 2 & $12 \%$ \\
\hline Castor fiber (castor) & 1 & $0,04 \%$ & 1 & $6 \%$ \\
\hline Ursus arctos (urso) & 1 & $0,04 \%$ & 1 & $6 \%$ \\
\hline Lynxpardinus (lince-ibérico) & 4 & $0,1 \%$ & 1 & $6 \%$ \\
\hline Aves & 2 & $0,1 \%$ & & \\
\hline \multirow[t]{2}{*}{ Alectoris rufa (perdiz-vermelha) } & 2 & $0,1 \%$ & 1 & $6 \%$ \\
\hline & NR & $\%$ & & \\
\hline Macrofauna & 267 & $10 \%$ & & \\
\hline Mesofauna & 441 & $16 \%$ & & \\
\hline Microfauna & 28 & $1 \%$ & & \\
\hline Indeterminado & 1683 & $63 \%$ & & \\
\hline Total & 2685 & & 17 & \\
\hline
\end{tabular}

Tabela 1 - Número de Restos (NR), Número de Restos Determinados (NRD) e Número Mínimo de Indivíduos (NMI) por grupo Taxonómico. 


\begin{tabular}{|c|c|c|c|c|c|c|c|c|c|c|c|c|c|c|c|}
\hline & $B$ & $\mathrm{O} / \mathrm{C}$ & $S$ & $C E$ & $C C$ & $A R$ & $E Q$ & ORC & $C F$ & $U A$ & $L P$ & MAC & MÊS & MIC & IND \\
\hline \multicolumn{16}{|l|}{ Esqueleto Cranial } \\
\hline Haste/Chifre & & & & 1 & & & & & & & & & & & \\
\hline Crânio & & 1 & 1 & & & & & & & & & 2 & 10 & & \\
\hline \multicolumn{16}{|l|}{ Maxilar } \\
\hline Mandíbula & 1 & 1 & & & & & & 1 & & & & 3 & 6 & & \\
\hline Dentes & 22 & 24 & 43 & 5 & 1 & 30 & 1 & $6(4)$ & & & & & & & \\
\hline \multicolumn{16}{|l|}{ Esqueleto Axial } \\
\hline Atlas & & 1 & 1 & & & & & & & & & & & & \\
\hline Costelas & & & & & & & & & & & & 3 & 21 & & \\
\hline Vértebras & & & & & & & & 2 & & & & 12 & 13 & & \\
\hline Vértebras Cervicais & & & & & & & & & & & & 11 & & & \\
\hline Vértebras Toráxicas & & & & & & & & & & & & 2 & 3 & & \\
\hline Vértebras Lombares & & & & & & & & & & & & 1 & 2 & & \\
\hline \multicolumn{16}{|l|}{ Membro Anterior } \\
\hline Escápula & & & $4(2)$ & & & & & $2(2)$ & & & & 1 & 2 & & \\
\hline Úmero & 1 & $2(1)$ & & & & & & $1(1)$ & & & & 2 & & & \\
\hline Rádio & 4 & 2 & & & & & & & & & & & & & \\
\hline Cúbito & 1 & 1 & 2 & 1 & & & & 3 & & & & 2 & & & \\
\hline Escafóide & & 2 & & & & & & & & & & & & & \\
\hline Semi-lunar & 1 & & & & & & & & & & & & & & \\
\hline Piramidal & 1 & & & & & & & & & & & & & & \\
\hline Capitato-trapezóide & & & & 1 & & & & & & & & & & & \\
\hline Os crochu & 2 & & & & & & & & & & & & & & \\
\hline Metacarpo & 4 & & 6 & & & & & & & $1(1)$ & & & & & \\
\hline \multicolumn{16}{|l|}{ Membro Posterior } \\
\hline Pélvis & 1 & $2(1)$ & $2(1)$ & $1(1)$ & & & & $6(4)$ & $1(1)$ & & & 2 & 1 & & \\
\hline Fémur & 1 & & & & & & & $1(1)$ & & & & 1 & & & \\
\hline Tíbia & & 2 & & & & & & $2(1)$ & & & & & & & \\
\hline Fíbula & & & 1 & & & & & & & & & & & & \\
\hline Calcâneo & $(1)$ & & 1 & $1(1)$ & & & & 4(4) & & & $1(1)$ & 1 & & & \\
\hline Astrágalo & $3(2)$ & & $4(4)$ & 2(1) & & & & & & & $2(2)$ & & & & \\
\hline Cubo-escafóide & 1 & & & & & & & & & & & & & & \\
\hline Navicular-Cubóide & & & & & & & 1 & & & & & & & & \\
\hline Navicular & & & & 1 & & & & & & & & & & & \\
\hline Metatarso & 2 & & & & & & & $3(2)$ & & & & & & & \\
\hline Metápode & $7(6)$ & $1(1)$ & $5(3)$ & $1(1)$ & & & & & & & & 1 & & & \\
\hline Falange I & $6(3)$ & & $10(4)$ & 1 & & & & & & & $1(1)$ & & & & \\
\hline Falange II & $1(1)$ & & $4(3)$ & $1(1)$ & & & & & & & & & & & \\
\hline Falange III & $3(1)$ & & $5(3)$ & & & & & & & & & 1 & & & \\
\hline Ossos longos & & & & & & & & & & & & 103 & 359 & 26 & \\
\hline Ossos indeterminados & & & & & & & & & & & & 119 & 24 & 2 & 1683 \\
\hline TOTAL & 63 & 39 & 89 & 15 & 1 & 30 & 2 & 31 & $\mathbf{1}$ & $\mathbf{1}$ & 4 & 267 & 441 & 28 & 1683 \\
\hline MNI & 2 & 1 & 2 & 1 & $I$ & & $I$ & 2 & I & I & 1 & & & & \\
\hline
\end{tabular}

Tabela 2 - Número de restos Determinados taxonomicamente (NRD) e não determinados (NR) por partes do esqueleto e Número Mínimo de Indivíduos (NMI). Entre parêntesis encontra-se o Número Mínimo de Elementos (NME). B - Bos sp. (gado bovino ou auroque); O/C - Ovis/Capra (ovelha ou cabra); S - Sus sp. (porco ou javali); CE - Cervus elaphus (veado); CC - Capreolus capreolus (corço); AR - Artiodactyla; EQ - Equus sp. (cavalo ou burro); ORC. - Oryctolagus cuniculus (coelho-bravo); CF-Castor fiber (castor); UA - Ursus arctos (urso); LP - Lynx pardinus (lince-ibérico); MAC - Macrofauna; MES - Mesofauna; MIC - Microfauna; IND - Indeterminado. 


\begin{tabular}{|c|c|c|c|c|c|c|c|}
\hline & Bos sp. & Ovis/Capra & Sus sp. & C. elaphus & C. capreolus & Artiodactyla & O. cuniculus \\
\hline \multicolumn{8}{|l|}{ Dentes Superiores } \\
\hline I & & & 3 & & & & \\
\hline i & & & 1 & & & & \\
\hline $\mathrm{C}$ & & & 2 & & & & \\
\hline $\mathrm{PM}$ & 2 & 2 & & & & & \\
\hline $\mathrm{P} 2$ & & 1 & & & & & \\
\hline $\mathrm{P}_{3}$ & & & 1 & & & & \\
\hline $\mathrm{P}_{4}$ & & & 1 & & & & \\
\hline $\mathrm{dp} 2$ & & & 1 & & & & \\
\hline $\mathrm{dp} 4$ & & 1 & & & & & \\
\hline \multicolumn{8}{|l|}{ Mi } \\
\hline \multicolumn{8}{|l|}{$\mathrm{M}_{2}$} \\
\hline $\mathrm{M}_{3}$ & & 1 & 1 & & & & \\
\hline $\mathrm{M}_{1} / 2$ & & 4 & 3 & & & & \\
\hline M & 1 & 5 & & 2 & 1 & & \\
\hline \multicolumn{8}{|l|}{ Dentes Inferiores } \\
\hline I & & 2 & 3 & 2 & & & 2 \\
\hline $\mathrm{C}$ & & & 2 & & & & \\
\hline $\mathrm{dp} 2$ & & 1 & & & & & \\
\hline \multicolumn{8}{|l|}{$\mathrm{dp} 3$} \\
\hline $\mathrm{dp} 4$ & 1 & & 1 & & & & \\
\hline $\mathrm{PM}$ & & & 2 & & & & \\
\hline $\mathrm{P}_{1}$ & & & 2 & & & & \\
\hline \multicolumn{8}{|l|}{$\mathrm{P} 2$} \\
\hline $\mathrm{P}_{3}$ & 1 & & & & & & \\
\hline $\mathrm{P}_{4}$ & 2 & & & & & & \\
\hline \multicolumn{8}{|l|}{ Mi } \\
\hline \multicolumn{8}{|l|}{$\mathrm{M} 2$} \\
\hline $\mathrm{M}_{3}$ & & 1 & 2 & & & & \\
\hline $\mathrm{Mi} / 2$ & 3 & 1 & 2 & & & & \\
\hline $\mathrm{M}$ & 3 & 2 & 1 & & & & 4 \\
\hline Dente Indeterminado & 9 & 3 & 15 & 1 & & 30 & \\
\hline Total & 22 & 24 & 43 & 5 & $\mathbf{I}$ & 30 & 6 \\
\hline
\end{tabular}

Tabela 3 - Número de restos por dente e por grupo taxonómico. 


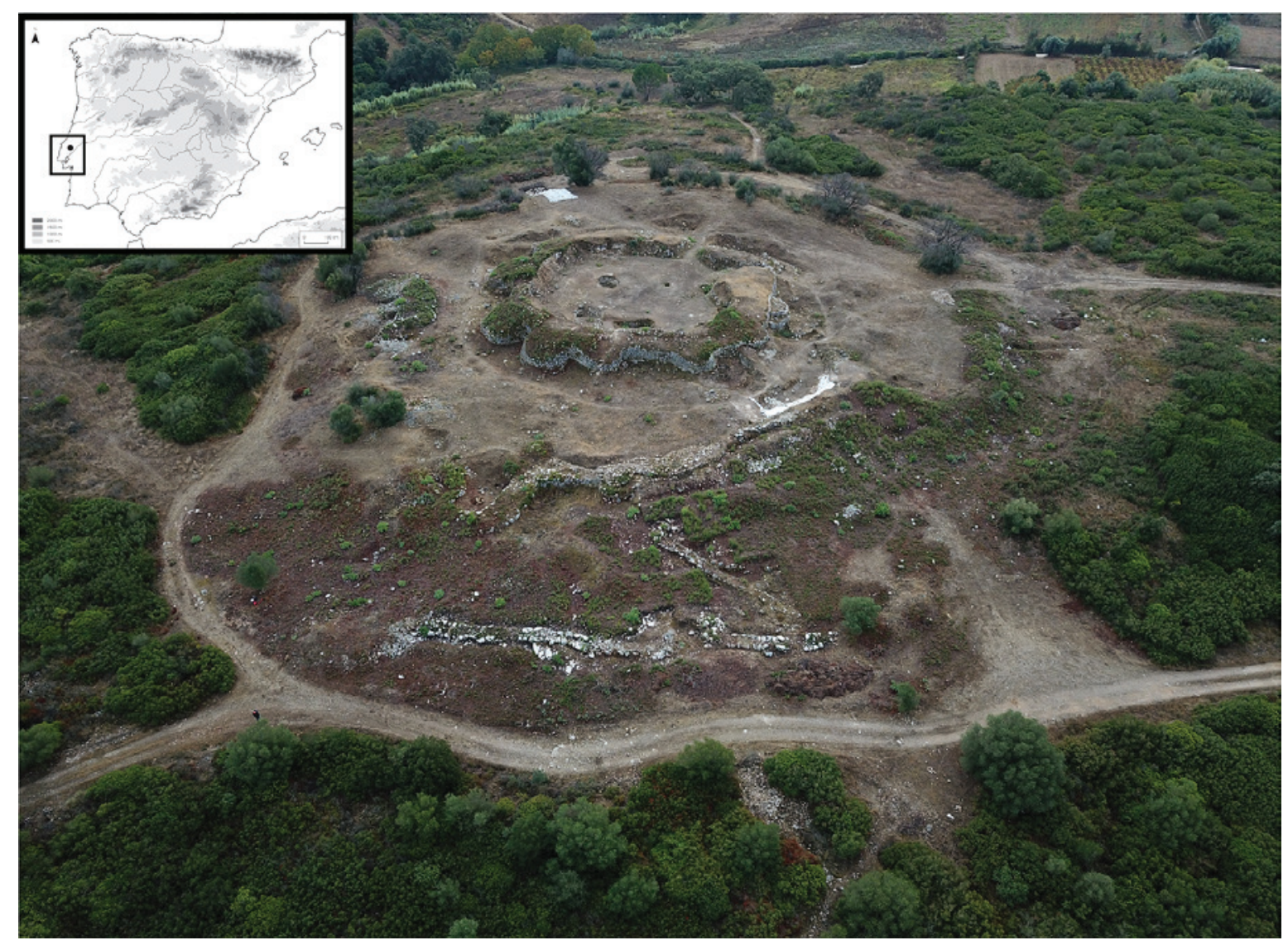

Figura 1 - Vila Nova de São Pedro - localização e aspecto geral do povoado calcolítico em 2018.

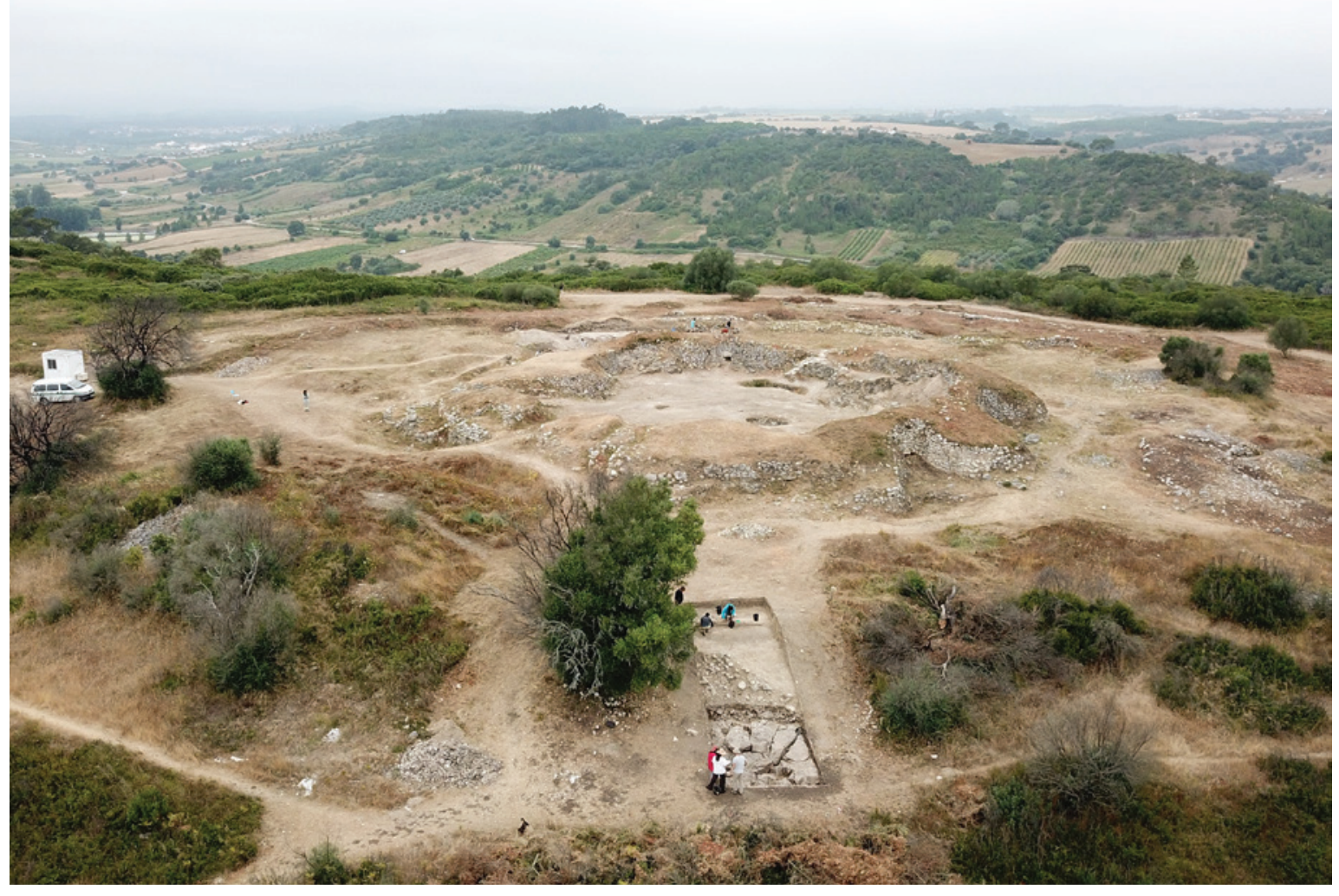

Figura 2 - Vila Nova de São Pedro visualizando-se em primeiro plano a sondagem 1 da Área 3. 


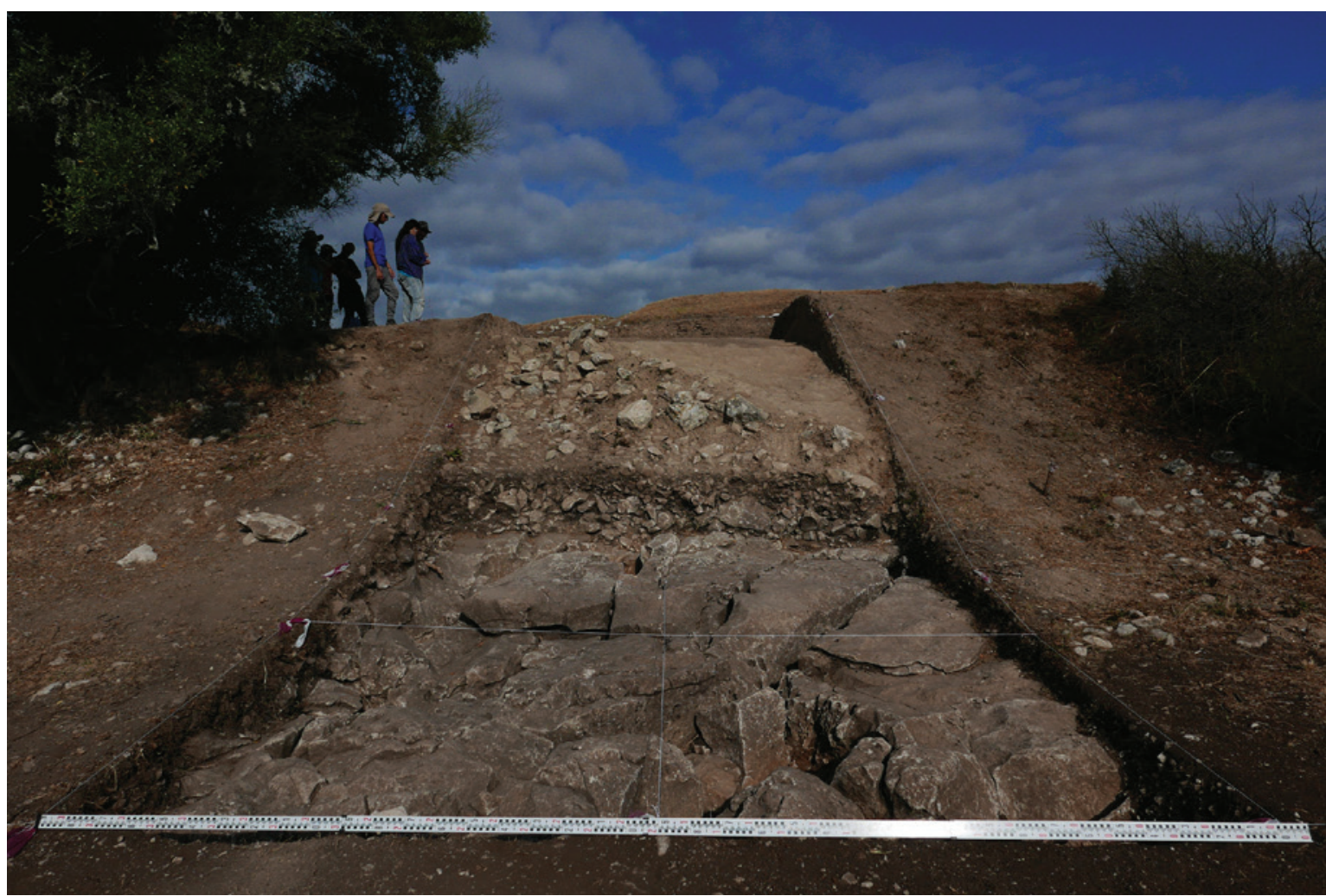

Figura 3 - Área 3, sondagem 1 - aspecto final da intervenção na plataforma inferior visualizando-se o substrato geológico e a entrada do algar.

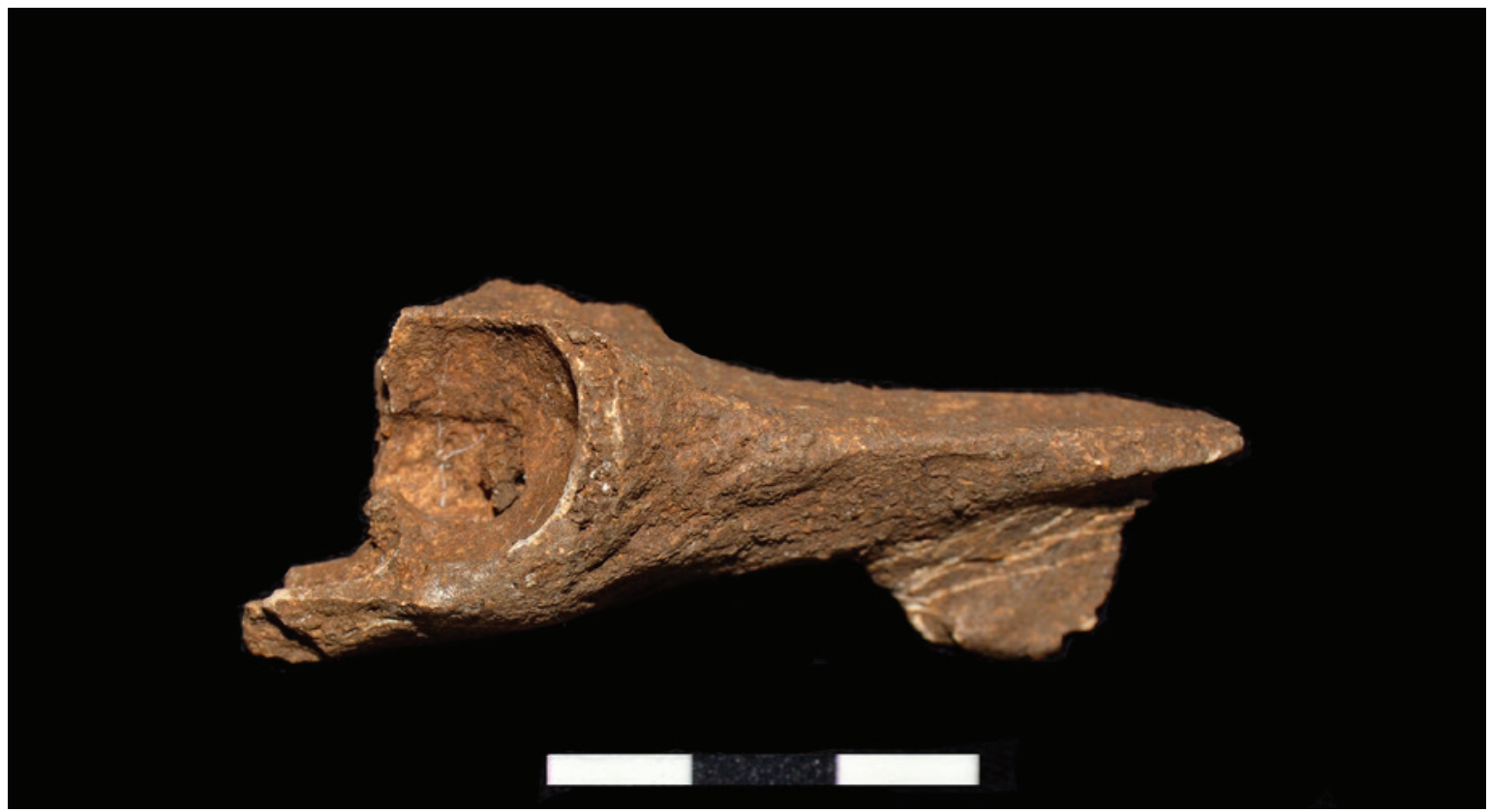

Figura 4 - Pélvis de Castor fiber (castor) recuperado na [305] - Área 3, sondagem 1, na campanha de 2017. 


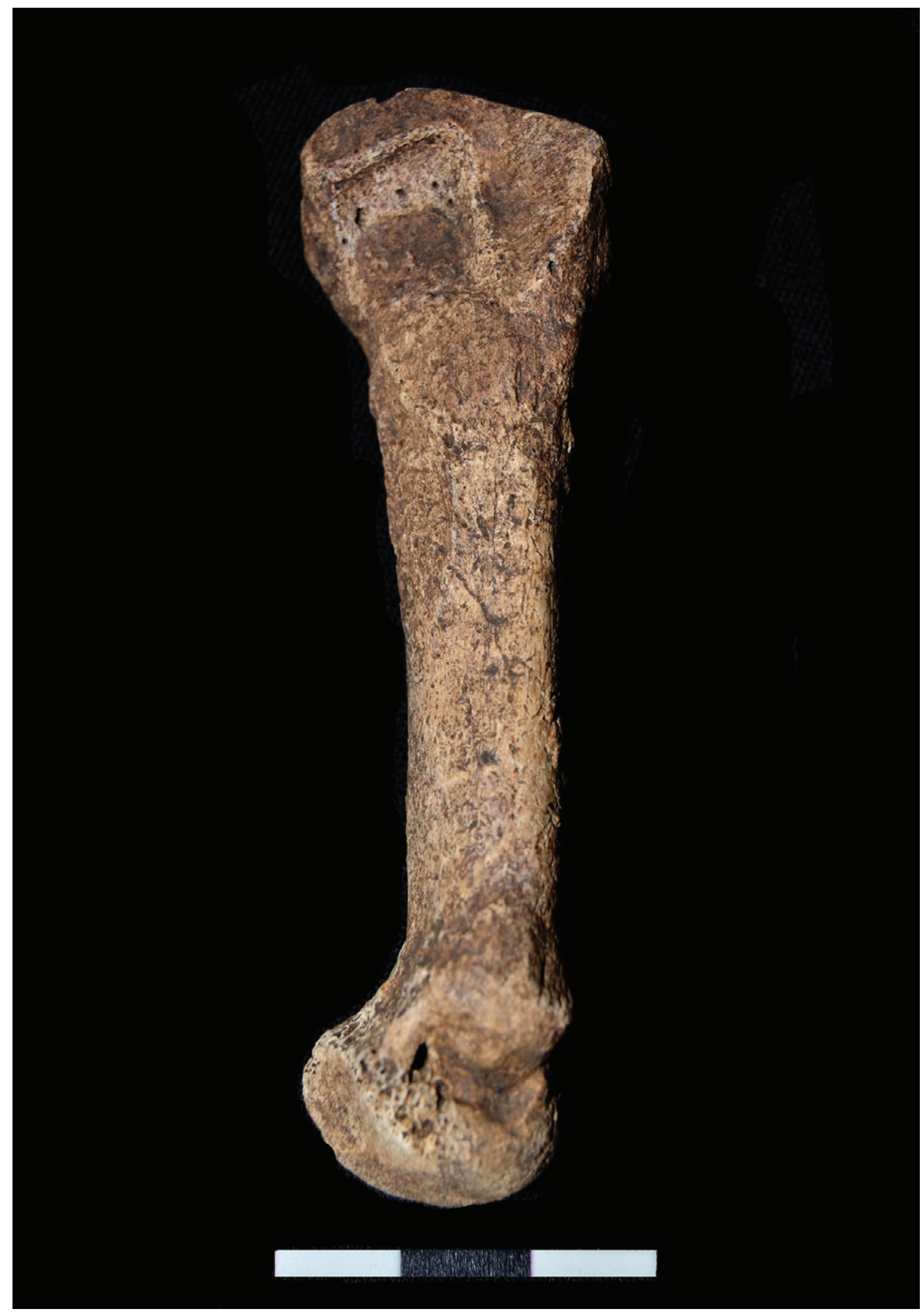

Figura 5 - Metacarpo IV completo de Ursus arctos (urso) recuperado da [305] - Área 3, sondagem 1, quadrado J5, na campanha de 2018 . 


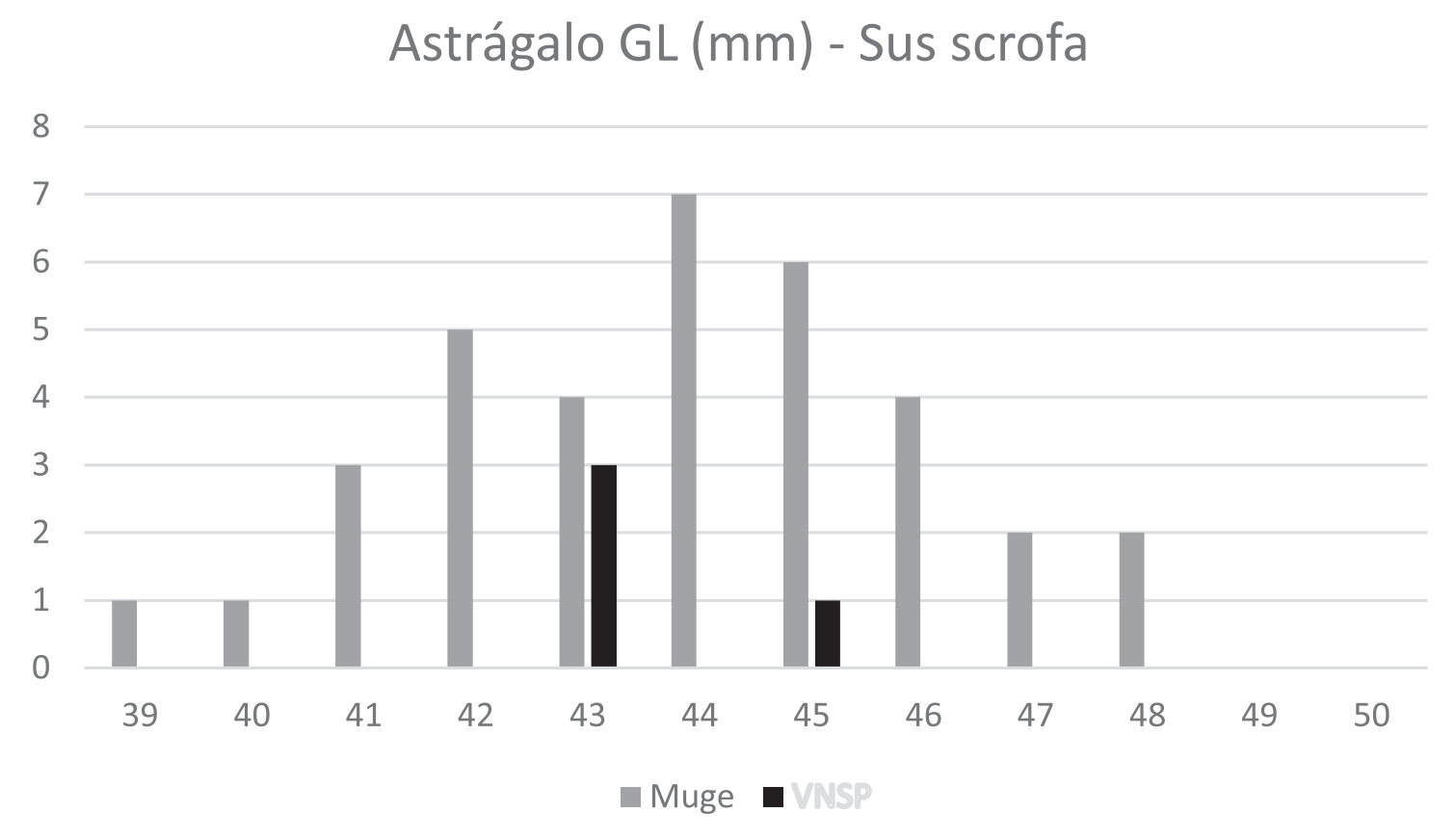

Figura 6 - Medida da altura máxima do astrágalo (GL) de Sus scrofa (em mm). Comparação das medidas de javali dos concheiros de Muge (Mesolítico, Detry, 2007) com as dos suídeos recuperados na [305] de Vila Nova de São Pedro.

\section{Falange I - Bos sp.}

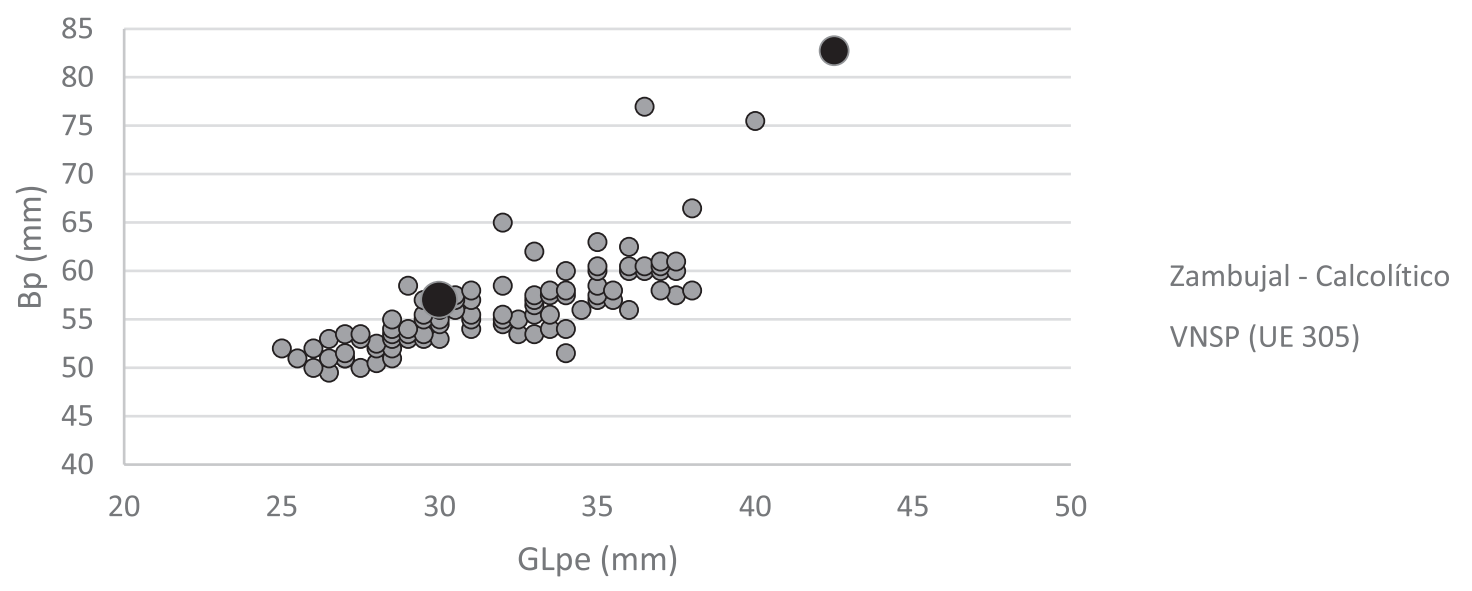

Figura 7 - Gráfico de dispersão com medidas da Falange I de Bos sp, dos sítios Calcolíticos do Zambujal e de Vila Nova de São Pedro. Medidas do Zambujal publicadas por Boessneck \& Driesch (1976). 


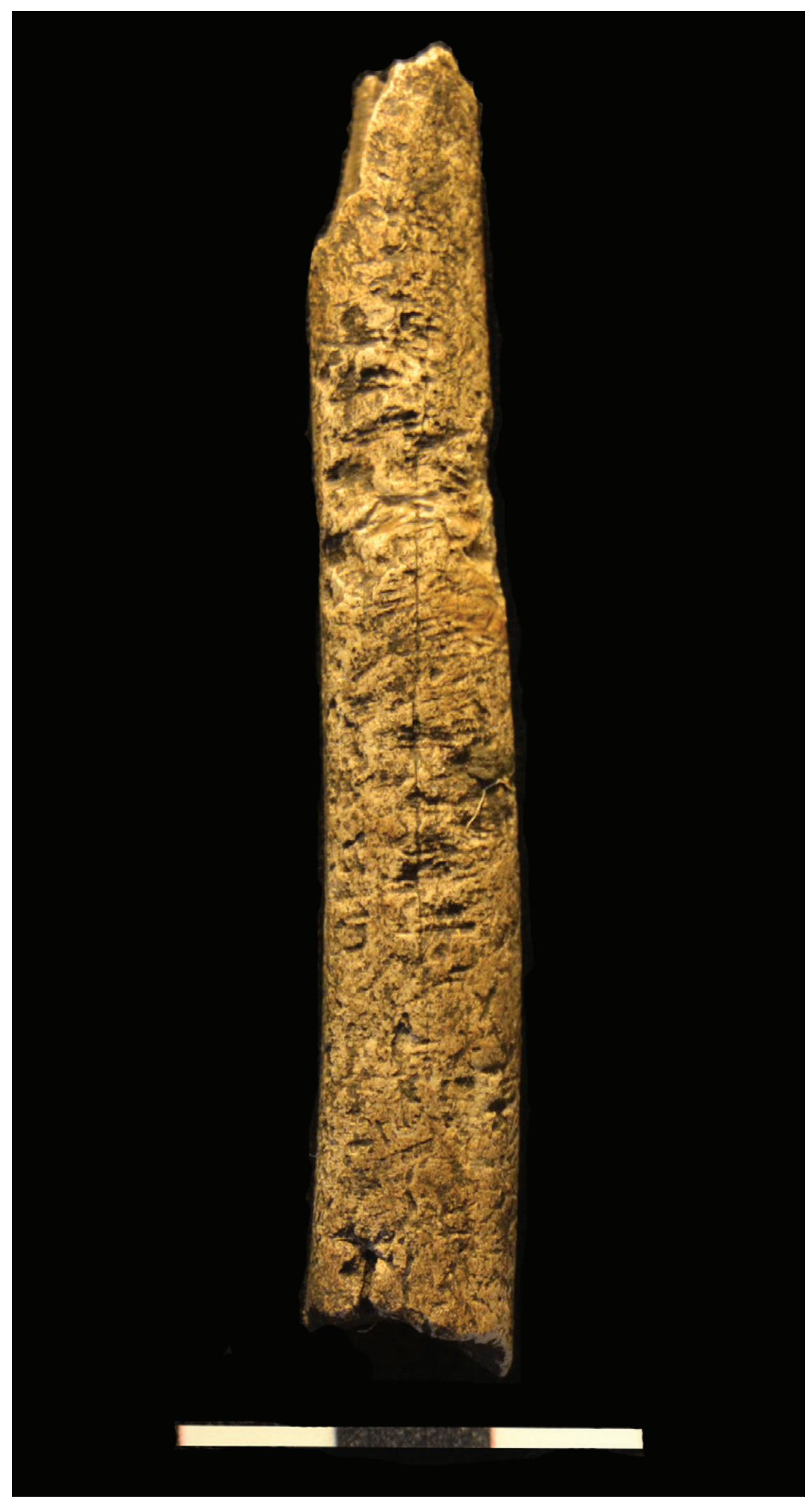

Figura 8 - Diáfise de tíbia de uma ovelha ou cabra com marcas de roedor. 


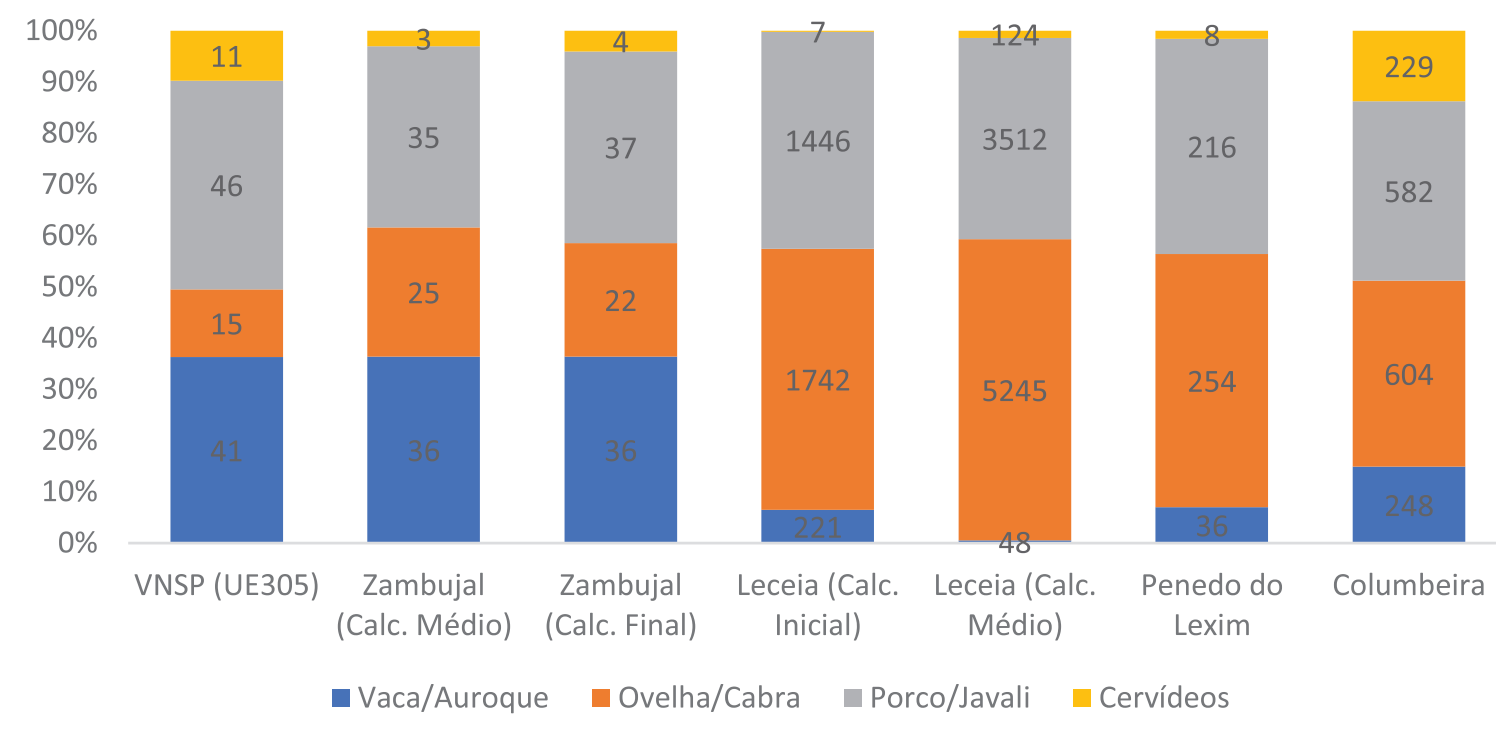

Figura 9 - Comparação dos quatro principais grupos taxonómicos presentes nos sítios arqueológicos do Calcolítico da Estremadura. Zambujal - Driesch \& Boessneck (1976); Leceia - Cardoso \& Detry (2001/2002); Penedo do Lexim - Moreno-Garcia \& Sousa (2015); Castro da Columbeira - Correia (2015). 


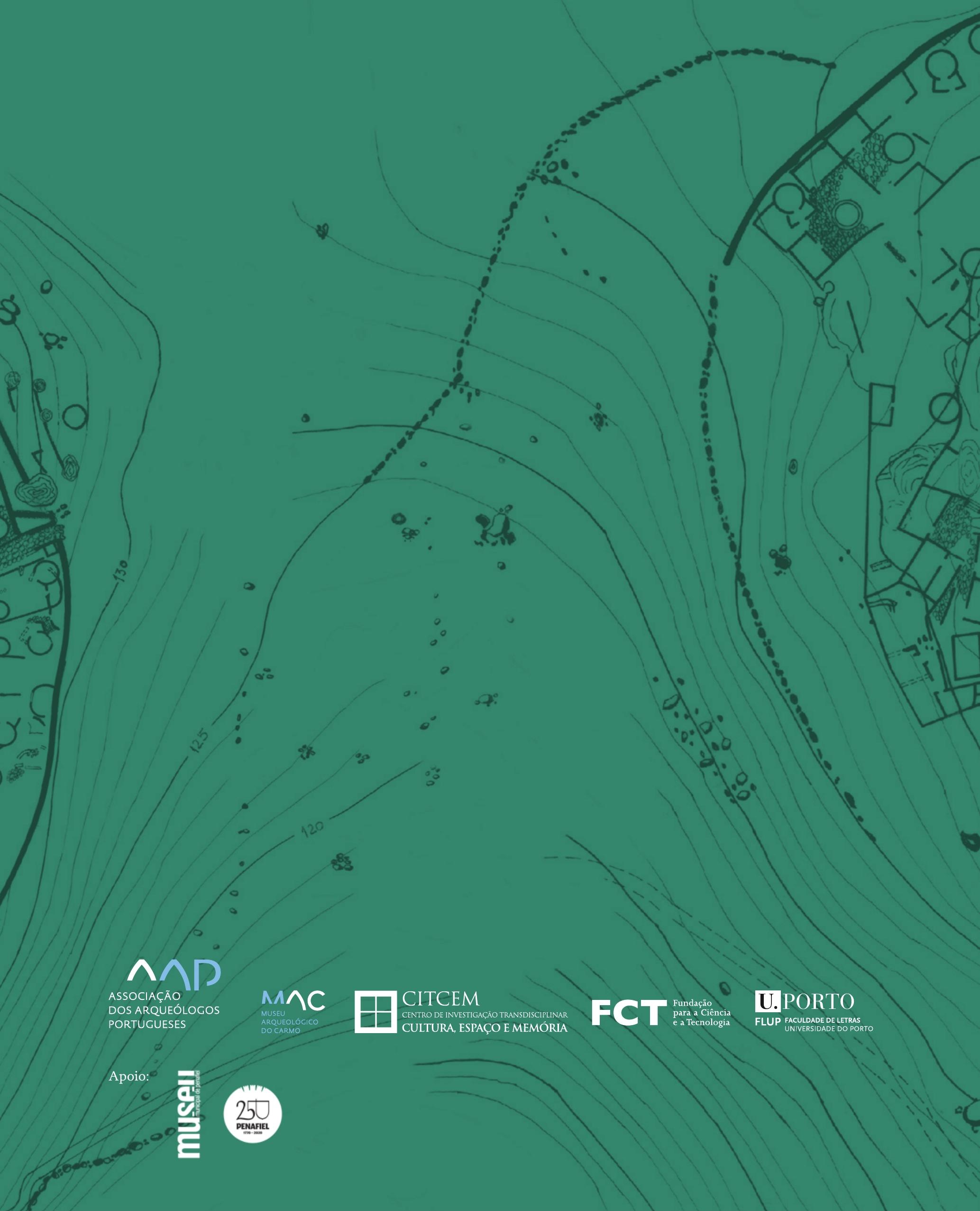

